\title{
EVALUATION OF A SURFACE TREATMENT TO IMPROVE THE EROSION RESISTANCE OF COQUINA STONE AT CASTILLO DE SAN MARCOS
}

Lawrence I. Knab James R. Clifton Nathaniel Waters

U.S. DEPARTMENT OF COMMERCE National Institute of Standards and Technology Center for Bullding Tochnology Galthersburg, MD 20899 



\section{EVALUATION OF A}

SURFACE TREATMENT TO

IMPROVE THE EROSION

RESISTANCE OF

COQUINA STONE AT

CASTILLO DE SAN

MARCOS
Lawrence I. Knab

James R. Clifton

Nathaniel Waters

U.S. DEPARTMENT OF COMMERCE Natlonal institute of Standards and Technology

Conter for Bullding Tochnology

Galthersburg, MD 20899

March 1990

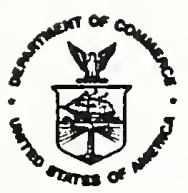

U.S. DEPARTMENT OF COMMERCE Robert A. Mosbacher, Secretary MATONAL INSTITUTE OF STANDARDS AND TECHNOLOAY John W. Lyone, Drrector 



\section{ABSTRACT}

A surface treatment, which was intended to improve the erosion resistance of coquina stone at the Castillo de San Marcos, was evaluated. The commercially-available stone surface treatment was claimed to contain both consolidating and water-repellent agents. Limited, short-term tests intended to simulate two types of erosion and to identify any severe degradation problems were conducted. Erosion of sawn surfaces caused by (i) mechanical abrasion from strokes with a steel brush, and (ii) a thin stream of water flow were investigated in the laboratory in different stone orientations. The erosion resistance, based on mass loss, of the treated stone was compared with that of the untreated stone. The results showed that, for some test conditions, the erosion resistance of the stone was significantly improved by the treatment. For the other test conditions, however, the erosion resistance of the treated and untreated specimens was not significantly different. Hot-cold cycling, freeze-thaw cycling, and ultraviolet light-intermittent moisture exposure tests were conducted and no degradation was observed. In some cases, a slight darkening was discernible on the surface of treated stone with sawn surfaces.

It was recommended that the surface treatment be applied to several trial areas at the Castillo de San Marcos, where erosion due to water flow or mechanical abrasion or both are occurring. The areas should be periodically observed and the erosion documented quantitatively, if possible, over an extended time period.

\section{Key Words}

Abrasion resistance; Castillo de San Marcos; consolidant; coquina stone; erosion resistance; moisture; preservation; stone surface treatment ; temperature; water repellent 

Page

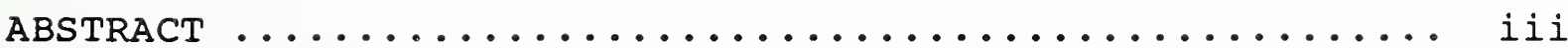

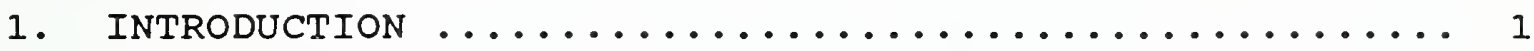

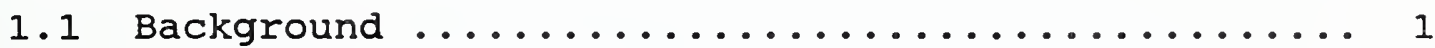

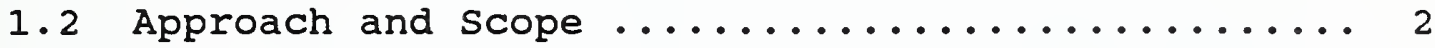

2. COQUINA STONE ............................... 2

3. SURFACE TREATMENT .......................... 3

4. TEST SPECIMENS, METHODS, AND PROCEDURES .......... 3

4.1 Application of Surface Treatment ............ 4

4.2 Erosion Resistance ...................... 5

4.2.1 Erosion by Mechanical Abrasion ......... 5

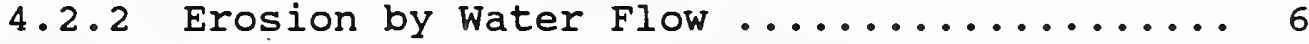

4.3 Temperature-Moisture Cycling Tests ........... 8

4.3.1 Hot-Cold Cycling in Presence of water .... 10

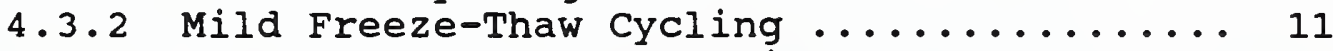

4.3 .3 Severe Freeze-Thaw Cycling ............. 11

4.4 Effects of $U V /$ water spray ................... 12

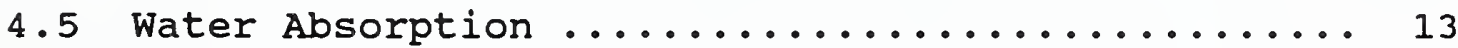

5. RESULTS, ANALYSIS, AND DISCUSSION .............. 13

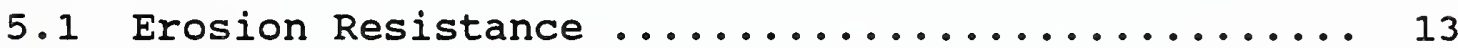

5.1.1 Erosion by Mechanical Abrasion ......... 13

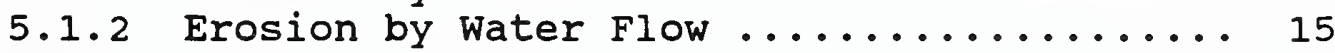

5.2 Effects of Temperature-Moisture and UV-Intermittent Moisture Cycling ............ 17

5.2.1 Temperature-Moisture Cycling ........... 17

5.2.2 UV-Intermittent Moisture Cycling ....... 17

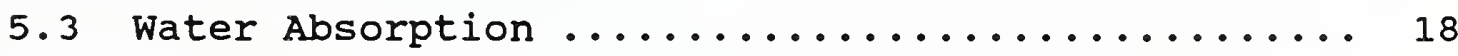


TABLE OF CONTENTS (Continued)

Page

6. SUMMARY AND CONCLUSIONS $\ldots \ldots \ldots \ldots \ldots \ldots \ldots \ldots \ldots \ldots$

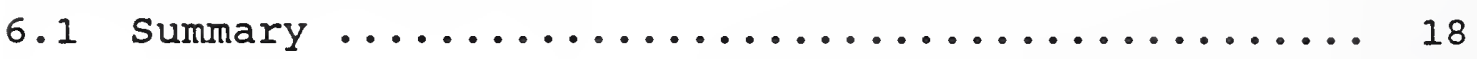

6.2 Conclusions $\ldots \ldots \ldots \ldots \ldots \ldots \ldots \ldots \ldots \ldots \ldots \ldots \ldots . \ldots \ldots$

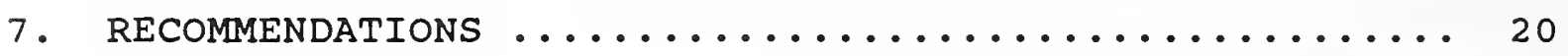

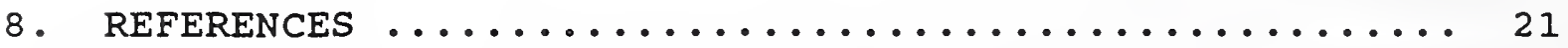

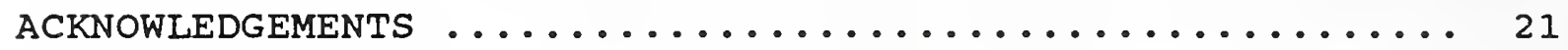

TABLES

FIGURES 


\section{INTRODUCTION}

\subsection{Background}

Castillo de San Marcos is located in St. Augustine, Florida, on the shore of Matanzas Bay, about a mile from the Atlantic Ocean. The Castillo de San Marcos is the oldest existing masonry fortress in the United states constructed with coquina stone. Construction started in 1672, and many modifications were made until the fort was finally deactivated in 1900.

Deterioration of the coquina stone at Castillo de san Marcos has occurred gradually. One primary cause of deterioration is erosion. Causes of erosion include wind and water (rain and runoff), and mechanical abrasion of the stone by human activity (foot traffic, sitting on stone, finger picking, etc).

An approach being considered for reducing the rate of deterioration is the use of preservative treatments (consolidants or water repellents, or both) for stabilizing the coquina. The National Park Service (NPS) requested that the National Institute of standards and Technology (NIST) evaluate a specific, commercially-available surface treatment for its ability to improve the erosion resistance of the coquina stone. In addition, NIST was asked to investigate potential incompatibilities between the treatment and the coquina stone which might result in damage (e.g., cracking in coquina) from temperature and moisture cycling. Information was needed on the possible degradation of the treatment caused by moisture and temperature cycling, and by ultraviolet (UV) light combined with intermittent moisture exposure. 
Although preferred, a detailed development of performance requirements and performance criteria was not conducted, due to the limited scope of the study. Rather, limited, short-term laboratory tests of treated stone were conducted and were intended to (a) simulate erosion and, (b) identify degradation problems caused by the exposure of the treated stone to severe environmental conditions.

\subsection{Approach and scope}

The commercially-available stone treatment, which was claimed to contain both consolidating and water-repellent agents, was selected by the NPS. The erosion resistance of treated coquina was compared with untreated coquina using sawn surfaces. The erosion resistance was measured by mass loss and was investigated by: (i) measuring the resistance to mechanical abrasion caused by brushing with a steel-bristled brush on dry coquina surfaces in each of three stone orientations, and (ii) measuring the resistance to erosion caused by water flow in two stone orientations.

Possible incompatibilities between the treatment and the coquina stone which could lead to damage (e.g., cracking in coquina) from cycling at extreme temperature and moisture conditions were investigated. In addition, evidence of possible degradation of the surface treatment by moisture and temperature cycling, and by UV light combined with intermittent moisture exposure, was sought. Temperature and moisture cycling included hot-cold and freeze-thaw cycling in the presence of moisture.

2. COQUINA STONE

Coquina stone was formed from lithification of sea shells and shell fragments [1]. In the coquina stone samples investigated 
in this study and in a previous study [2], the shells in the stone were seen to be arranged in a fairly uniform bedding plane pattern (figure 1). This pattern resulted in a highly porous stone with high water absorption, low dry density, and low compressive strength [2].

\section{SURFACE TREATMENT}

The surface treatment used was a one-component, low-viscosity material which, according to the manufacturer, contained a combination of ethyl silicate for consolidation, and a silane for water-repellency. Technical data for the uncured consolidant (prior to applying to stone) as reported by the manufacturer are: 1. Color: neutral to pale yellow

2. Active Mineral Content (solids): 75 percent by weight

3. Viscosity $\left(2 \mathrm{~mm} \mathrm{DIN}^{\mathrm{a}}\right.$ cup at $25^{\circ} \mathrm{C}$.) : approx. $60 \mathrm{sec}$

4. Solvent: organic solvents

5. Flash Point: below $21^{\circ} \mathrm{C}$.

4. TEST SPECIMENS, METHODS, AND PROCEDURES

The coquina stone used for the laboratory study was "nonhistoric" as it was not taken from the Castillo de San Marcos, but obtained from the vicinity of st. Augustine, Florida. The stone was shipped to NIST and was cut with a water-cooled saw to the dimensions required for the tests. The stone was cut either parallel or perpendicular to its bedding planes (figure 1(c)). Stone orientations for specimens were chosen relative to the bedding planes. In this report, all stone dimensions are reported to the nearest $1 \mathrm{~cm}$ (if no decimal places given) or 0.5 $\mathrm{cm}$ (if tenths of $\mathrm{cm}$ are shown).

- Test method not available. 


\subsection{Application of Surface Treatment}

The surface treatment was applied to specimens which were either thoroughly air-dried under room condtions (in this report, refers to about $20^{\circ} \mathrm{C}$ and approximately 50 percent relative humidity) or oven dried at $60^{\circ} \mathrm{C}$. All specimens, except those used for the temperature-moisture cycling tests (Section 4.3), were treated according to the supplier's recommendation as follows. The specimens were totally immersed in the treatment solution for 2 minutes, air dried for 60 minutes, and totally immersed again for 2 minutes. Based on preliminary tests using the above procedure on 3 specimens, the loading (grams of treatment solids $/ \mathrm{cm}^{3}$ of coquina) after 4 weeks of air drying at room temperature, ranged from about 0.061 to $0.067 \mathrm{~g}$ solids $/ \mathrm{cm}^{3}$ of coquina. An additional specimen, however, after only one week of air drying had an estimated loading of $0.055 \mathrm{~g}$ solids $/ \mathrm{cm}^{3}$, reflecting variation in the loading. It is possible that the loading using the above procedure could vary considerably and may depend on other factors, such as the variability in the density of the coquina. For example, preliminary measurements of the "dry density" were determined by dividing the oven-dry (or thoroughly air-dried) weight of a specimen by its measured approximate volume (length $\mathrm{x}$ width $\mathrm{x}$ height). The range of these measurements was about 1.6 to $1.8 \mathrm{~g} / \mathrm{cm}^{3}$, in contrast to a range of "dry density" values of 1.36 to $1.55 \mathrm{~g} / \mathrm{cm}^{3}$ found for a small sample of historic coquina at the Castillo de San Marcos [2].

In some cases, the application of the surface treatment to sawn surfaces appeared to have caused a slight darkening in the appearance of the stone. 
4.2.1 Erosion by Mechanical Abrasion

A mechanical abrasion test, consisting of cross strokes using a brush with steel bristles, was developed. The test used a modification of a washability machine as shown in figure 2. A steel-bristled brush was used, with lead weights attached to the top of the brush (figure 2(b)), to provide additional abrading force. A special holder for the brush was made. The dimensions of the steel bristles of the brush (all the bundles of steel bristles were measured as an entity) were $3.5 \mathrm{~cm} \mathrm{high,} 4.4 \mathrm{~cm}$ wide, and $8.7 \mathrm{~cm}$ long. The $4.4 \mathrm{~cm}$ brush dimension was perpendicular to the direction of the brush movement and the 8.7 cm dimension was parallel to it (figure $2(a)$ ). The total mass of the brush, brush holder, and lead weights was $700 \mathrm{~g}$.

The coquina specimens used for mechanical abrasion testing were $20 \mathrm{~cm}$ long, $10 \mathrm{~cm}$ wide, and $1.3 \mathrm{~cm}$ thick. They were cut and tested in three different stone orientations (1, 2, and 3) relative to the bedding planes (figure 3 ). In each of the 3 stone orientations, there were 3 specimens treated with surface treatment and 3 untreated control specimens. The specimens were oven dried to constant mass at $60^{\circ} \mathrm{C}$. After oven drying, the specimens were treated (Section 4.1) and then cured at room temperature for at least 4 weeks prior to being abraded. (The

b The apparatus which was modified was a Gardner straight Line Washability and Abrasion Machine, No. M 781, made by Gardner Laboratory, Inc., Bethesda, MD. Certain manufacturers' names, and names of commercial equipment, instruments, and materials are identified in this report to adequately specify the experimental procedure. Such an identification does not imply recommendation or endorsement by the National Institute of standards and Technology, nor does it imply that the equipment, instruments, or materials identified are necessarily the best available for the purpose. 
supplier recommended that treated specimens be cured at least 3 weeks before being tested). Both the treated and untreated specimens were stored under room conditions until they were tested.

The amount of stone abraded was measured by mass loss. To minimize mass loss due to causes not associated with the abrasive force of the steel bristles, the sides and bottoms of the specimens were taped with duct tape. After taping, the specimens were air blasted to remove loose particles and dust, weighed, and mounted in the apparatus using wood spacers (figure $2(a)$ ) to prevent movement of the specimens during testing. During testing, the brush oscillated back and forth along the $20 \mathrm{~cm}$ specimen dimension, resulting in an abraded area of about $88 \mathrm{~cm} .{ }^{2}$ (4.4 cm brush width $\mathrm{x}$ approximately $20 \mathrm{~cm}$ specimen length). One cycle consisted of a back $(20 \mathrm{~cm})$ and forth $(20 \mathrm{~cm})$ brush movement. Each of the three stone orientations required a different number of cycles to obtain a measurable mass loss. After cycling, the specimen was removed, the abraded surface air blasted to remove loose particles and dust, and the specimen weighed. In almost all cases, the total number of cycles was 2500 , 5000, or 5500 applied at a rate of about 2200 cycles/hour. For some specimens, the cycles were not applied continuously, requiring two or more cycling periods to obtain the intended number of cycles.

In several cases during testing, the brush was thrown off of its path, which was probably caused by the deep rutting.

\subsubsection{Erosion by Water Flow}

The erosion resistance due to water flow was measured by the mass loss of the specimen caused by a stream of tap water striking the surface. The test setup shown in figure 4 was used. It included 
a water tank (figure 4a), and a frame (figures 4 (b) and 4 (c)) that held the stone at a $45^{\circ}$ angle relative to a stream of water, which struck the specimen's surface. The water tank provided water flow to each of 12 needle valves. The water level in the tank was kept at approximately the same level during testing.

The stream of water which struck the specimen usually ran continously about 6 to $8.5 \mathrm{~h} /$ day during workdays and was shut off at other times. The stream of water, about $0.3 \mathrm{~cm}$ in diameter, fell a distance of $57.8 \pm 1.2 \mathrm{~cm}$. The flow rates were measured for each of the 12 needle valves (figure $4(\mathrm{~b})$ ) at least once per day, and the average (based on 12 flow rates) almost always ranged from 200 to $260 \mathrm{ml} / \mathrm{min}$. Each time the flow rates were measured, the coefficient of variation ((standard deviation/average) $\times 100$ ) of the 12 individual flow rates was calculated; its value was almost always between 3 and 6 percent. The flow rates were adjusted daily, if necesary, to maintain approximately the same flow rate for all 12 specimens.

The coquina specimens used for the water flow testing were $10 \mathrm{~cm}$ long by $10 \mathrm{~cm}$ wide by $2.5 \mathrm{~cm}$ thick. The specimens were positioned in the two stone orientations, 4 and 5 , relative to their bedding planes as shown in figure 5. In each of the two stone orientations, there were 3 treated specimens and 3 untreated control specimens. After thoroughly drying under room conditions, the specimens were treated (Section 4.1), and then cured under room conditions for at least 8 weeks prior to being subjected to water flow. To estimate the mass loss due to water erosion, both the treated and untreated specimens were thoroughly air-dried under room conditions prior to being subjected to water flow, weighed, and then after being subjected to about $4100 \mathrm{~L}$ of water flow, were oven-dried to constant mass at 60 to $63^{\circ} \mathrm{C}$, and weighed again. Then the same specimens were subjected to approximately 1550 additional liters of water, oven dried to 
constant mass at 60 to $63^{\circ} \mathrm{C}$, and reweighed.

Preliminary tests were conducted to determine the effects of two factors that could influence the mass loss: (i) difference in mass between specimens which were "thoroughly air-dried under room conditions" and a "oven-dried to constant mass at 60 to $63^{\circ} \mathrm{C}$ " and, (ii) mass loss due to handling the specimens. From these tests, it was estimated that the mass of the air-dried specimens exceeded the oven-dried specimens by at most $1 \mathrm{~g}$, and that the effect of mass loss due to the handlings a specimen received was almost always less than $1 \mathrm{~g}$. An excess of moisture in the air-dried compared with the oven-dried specimens would result in an apparent mass loss which was slightly greater than if both masses were based on oven-dried specimens. Similarly, a loss of coquina particles during handling would result in an apparent mass loss which was slightly greater than if no handling losses occurred. However, because the effects of these two factors most likely occurred on both the treated and untreated specimens and because their effects were relatively small, their combined effect was not considered important in the mass loss analysis given in section 5.1.2.

\subsection{Temperature-Moisture Cycling Tests}

Three different temperature-moisture cycles were applied to the same 12 specimens. First, 21 hot-cold cycles were performed, followed by 29 mild freeze-thaw cycles, and finally 4 severe freeze-thaw cycles were conducted. (The conditions are described below.). The intent was to simulate several scenarios of cycling involving temperature-moisture extremes that the treated stone might experience at the Castillo de San Marcos. The highest temperatures for the hot cycles ranged from 58 to $84^{\circ} \mathrm{C}$, which were probably at, or in excess of, the maximum expected surface 
temperature ${ }^{c}$. The lowest temperatures for the severe freeze-thaw cycles ranged from -14 to $-9^{\circ} \mathrm{C}$, and were at, or below the expected lowest temperature experienced near the Castillo de San

Twelve cubic specimens, $10 \mathrm{~cm}$ on a side, were tested. Six cubes which were to be treated were first air dried, weighed, and then partially immersed in a depth of about $1.3 \mathrm{~cm}$ of treatment solution for 15 seconds. For 3 of the 6 cubes, the treatment solution was allowed to migrate inwards parallel to the bedding planes and for the remaining 3 cubes, the treatment solution was allowed to migrate inwards perpendicular to the bedding planes.

This procedure resulted in a treatment penetration depth of about $3.5 \mathrm{~cm}$, giving a loading of 0.02 to $0.05 \mathrm{~g}$ solids $/ \mathrm{cm}^{3}$ of treated coquina. This result was based on the weight increase averaged over the $3.5 \mathrm{~cm}$ penetration depth and was determined by weighing the cubes after they had cured for 5 weeks, prior to the beginning of the cycling process.

As shown in figure 6 , the 12 cubes were packed adjacent to each other. Three of the treated cubes were placed with their bedding planes parallel to the heat flow direction and the other 3 treated cubes had their bedaing planes perpendicular to the heat flow direction. The 6 untreated cubes were placed similarly, with 3 in each bedding-plane direction. The cubes were placed in

c A very rough estimate for the range of surface temperature of the coquina stone was obtained from figure 3 , page 13, of reference 3 , where calculated roof surface temperatures ranged from approximately $50^{\circ} \mathrm{C}$, for a white roof, to $70^{\circ} \mathrm{C}$ for a black roof, corresponding to a $35^{\circ} \mathrm{C}$ outside ambient air temperature.

d This statement is based on weather records [4] indicating that the record lowest temperature in St. Augustine measured for the period of $1951-1972$ was $-8.9^{\circ} \mathrm{C}$. 
a stainless steel pan so that treated sections were facing the heat source.

With the hot-cold and mild freeze-thaw cycles, either cool tap water or a mixture of crushed ice and water was added to the stainless steel pan so that the water level was $6.4 \mathrm{~cm}$ deep for all the cubes (i.e., for the treated cubes, the water level was about $0.3 \mathrm{~cm}$ below the treated section). With the severe freezethaw cycles, the cubes were soaked with cool tap water, drained and covered with wet cloth, and then placed in a freezing cabinet.

The cube temperatures were measured using thermocouples sandwiched between the cube sides, 2.5 to $3.8 \mathrm{~cm}$ below the top surfaces. The cube temperatures are approximations to the temperature range of all the cubes because only two locations were periodically monitored.

\subsubsection{Hot-cold Cycling in the Presence of Water}

The 19 hot-cold cycles were applied to the cubes as follows. Prior to exposing the cubes to heat lamps (figure 6), the pan containing the cubes and cool tap water was placed in a refrigerated cabinet between 15.5 and $89.5 \mathrm{~h}$, cooling the cubes and water between 4.2 and $8.4^{\circ} \mathrm{C}$. Two temperature measurements of the cubes were taken, one near the center of the pan of cubes, and the other near the edge of the pan. The pan of cubes was then removed from the cool temperature cabinet and placed under the 12 heat lamps (figure 6), for 5.2 to $7.7 \mathrm{~h}$, heating the cubes to 57.8 to $83.7^{\circ} \mathrm{C}$. At the end of the heating cycle, the heated water, which had dropped 1.3 to $2.5 \mathrm{~cm}$ in depth due to evaporation, was siphoned from the pan and replaced with cool tap water to the $6.4 \mathrm{~cm}$ depth. The pan was then returned to the cool cabinet and the process was repeated for a total of 19 cycles. 
An additional two cycles were run, with minimum cube temperatures of -0.3 to $4.4^{\circ} \mathrm{C}$ and maximum cube temperatures of 51.4 to $64.0^{\circ} \mathrm{C}$, with the cubes being heated for $2 \mathrm{~h}$. In one of these cycles during cooling, a thin layer of ice formed when the temperature reached freezing, and in the other cycle crushed ice was added to the water at the beginning of the cooling cycle.

\subsubsection{Mild Freeze-Thaw Cycling}

In the mild freeze-thaw cycling, 29 cycles were run where the temperature in the cubes was near or below freezing. These cycles were conducted as follows. First, crushed ice and water were put into the pan containing the cubes, and then the pan was placed in a cooling chamber for 6 to $8 \mathrm{~h}$ (one cycle was $10 \mathrm{~h}$ ). During that time, the minimum cube temperatures ranged from -1.8 to $2.1^{\circ} \mathrm{C}$, with at least one of the two measured temperatures below freezing in 23 of the 29 cycles. In almost all cycles there was a thin, solid, ice sheet over the water-crushed ice solution prior to the pan being removed from the cooling chamber. After removal from the cooling chamber, the pan warmed to room temperature until the beginning of the next cycle.

After completing the 29 cycles, the 12 cubes were oven dried to constant mass at $63^{\circ} \mathrm{C}$ to determine their mass loss.

\subsubsection{Severe Freeze-Thaw Cycling}

Four severe freeze-thaw cycles were conducted. The cubes were immersed and covered in cool tap water for 1 hour, the water drained, and the cubes then covered with wet cloths and placed in a freezing chamber. The cubes remained in the chamber for about $24 \mathrm{~h}$, during which time they cooled to -11.2 to $-9.4^{\circ} \mathrm{C}$ for three of the four cycles, and to -13.7 to $-12.9^{\circ} \mathrm{C}$ during the fourth 
cycle. Then the cubes were allowed to return to room temperature and the cycle was repeated.

After completion of the 4 cycles, the cubes were oven dried at $63^{\circ} \mathrm{C}$ to determine their mass loss.

\subsection{Effects of UV/Water Spray}

The effects of UV light and intermittent water spray on treated and untreated stone samples were investigated under controlled laboratory conditions using a xenon arc-type (water-cooled) light exposure apparatus with water spray. The apparatus ${ }^{\circ}$ was of the type described in ASTM G 26-88 [5]. The black panel temperature [5] was approximately $72^{\circ} \mathrm{C}$ (taken when water spray was not spraying).

Specimens measuring 11 by 11 by $2.7 \mathrm{~cm}$ thick were used, with one 11 by $11 \mathrm{~cm}$ surface exposed to the UV light and intermittent water spray. Three treated specimens were placed with their bedding planes parallel to the direction of the UV light and another 3 treated specimens had their bedding planes perpendicular to the direction of the light. Six untreated specimens were placed similarly, with 3 in each bedding-plane orientation.

The specimens were exposed in the light exposure apparatus for 1990 hours. During this time, the specimens were exposed constantly to a UV source and were sprayed continuously with deionized water for 30 minutes in each 24 hour exposure period. The specimens were removed and the surfaces exposed to UV light and water spray were examined for any visible indications of deterioration or color change and the specimens were weighed to

- The light exposure apparatus was Model 65-WR 123 Weatherometer, Atlas Electric Devices Co., Aug. 1978. 
determine mass loss.

\subsection{Water Absorption}

The absorption of treated and untreated stone was measured as follows. The specimens were 3.8 by 3.8 by $28.6 \mathrm{~cm}$. Six specimens, 3 in each of two bedding plane orientations, were treated. Additionally, 6 control specimens, 3 in each of two bedding plane orientations, were not treated.

The treated specimens (cured under room conditions for three weeks) and the untreated specimens were oven dried at $53^{\circ} \mathrm{C}$ for 72 $\mathrm{h}$, weighed after cooling for about $1 \mathrm{~h}$, immersed in distilled water at room temperature for 48 to $49 \mathrm{~h}$, and surface dried and weighed. The absorption was calculated in weight percent as given in ASTM C97 [6]. The procedure required that the specimens be surface dried with a damp cloth, which was somewhat arbitrary because of the porous texture of the stone. The results, however, were considered adequate to distinguish substantial differences in water absorption between treated and untreated stone.

\section{RESULTS, ANALYSIS, AND DISCUSSION}

\subsection{Erosion Resistance}

\subsubsection{Erosion by Mechanical Abrasion}

The mass loss results are shown in table 1 and figure 7 for the mechanical abrasion tests of the treated versus untreated specimens in each of the three stone orientations. There was a 
statistically significant ${ }^{f}$ difference in the average mass loss in the untreated $(7.4 \mathrm{~g} / 1000$ cycles) compared with the treated $(1.5$ g/1000 cycles) samples in stone Orientation 1 (figures 3,7 and $8)$. In the other two stone orientations, the average mass loss for the untreated exceeded that for the treated, but the results were not statistically significant ${ }^{8}$.

It was considered inappropriate to use the standard deviation to measure the precision because of the relatively large differences in the averages and standard deviations in the treated compared with the untreated specimens, for a given stone orientation. Rather, the coefficient of variation was used as a measure of the precision.

The coefficient of variation values (table 1) were very large for Stone orientations 2 and 3 , with values ranging from 54 to 76 percent. The coefficient of variation values for stone orientation 1 were lower ( 17 and 19 percent). For a given stone orientation, the variability of the treated compared to the untreated specimens did not appear to be much different. The coefficient of variation values suggest that the variation when testing in stone orientations 2 and 3 was greater than that in stone orientation 1.

Residual water repellency was tested in the 9 treated specimens after the abrasion testing had been completed. In the 9 dried

$f$ In this report, it was considered that the difference between two averages was statistically significant if the "t" statistic value (calculated from Natrella [7], page 3-23) was 3 or more. With stone orientation 1 (figure 3), the "t" statistic was 7.9, and indicated that the difference between the average mass losses for the treated and untreated specimens was statistically significant.

8 The "t" values were 1.4 and 0.6 for stone Orientations 2 and 3 , respectively (figures 3 and 7 ). 
specimens, water still beaded rather than being immediately absorbed into the surface in the abraded area. This is in contrast to dried untreated specimens, where water dropped onto the surface was immediately absorbed into the stone. Water beading indicated that at least some of the water repellancy was still present.

\subsubsection{Erosion by Water flow}

Table 2 lists the mass losses for treated compared with untreated specimens and for the two stone orientations (figure 5). The volume of water applied to the specimens was about $5650 \mathrm{~L}$. Mass loss was determined after approximately $4100 \mathrm{~L}$ of flow and again after approximately $5650 \mathrm{~L}$. These two ranges of water-flow volume are reported in table 2: (a) 0 to $4100 \mathrm{~L}$, and (b) 4100 to $5650 \mathrm{I}$. The mass losses in the range of 0 to $4100 \mathrm{~L}$ are shown in figure 9. The influences of using air-dried and oven-dried masses in the range of 0 to $4100 \mathrm{~L}$, and also that of mass loss due to handling, are discussed in section 4.2 .2 and were not considered important. The mass losses shown in table 2, therefore, were considered good approximations to the actual mass losses.

In the water-flow volume range of 0 to $4100 \mathrm{~L}$, the average mass loss for the treated compared with the untreated specimens was significantly different ${ }^{h}$ in both stone orientations (see figure 9 ). Based on the averages in table 2, the mass losses of the untreated specimens were 2.4 and 2.6 times that of the treated specimens for stone orientations 4 and 5, respectively. The average mass losses in the water-flow volume range of 4100 to

h The "t" values were 3.3 and 3.5 for stone orientations 4 and 5 , respectively (figure 5 ). Therefore, the difference between the average weight losses for the treated and untreated specimens was considered statistically significant in both the stone orientations. See footnote "f". 
5650 L were about the same for the treated compared to the untreated specimens; the reason for this is not known.

Figures 10 and 11 show examples of the surface condition for treated and untreated specimens with stone orientations 4 and 5 (figure 5), respectively, after the specimens had received 5570 to 5830 L of water flow. As evident from the figures, a small increase in surface erosion appears to have occurred in the untreated compared with the treated specimens.

Residual water repellency was tested in the 6 treated specimens after the water flow testing had been completed. In 4 of the 6 dried specimens, water still beaded rather than being immediately absorbed into the surface in the vicinity of where the water had struck the specimens during water-flow testing. This is in contrast to dried untreated specimens, where water dropped onto the surface was immediately absorbed into the stone.

For the same reasons as given in section 5.1.1, the coefficient of variation was used as a measure of precision. In the range of 0 to $4100 \mathrm{I}$ and in both stone orientations, the coefficient of variation values for the treated specimens were lower than for the untreated specimens. A possible explanation is that the treatment provided a more uniform resistance to erosion compared with the untreated specimens. In the range of 4100 to $5650 \mathrm{~L}$, the coefficient of variation values are not considered meaningful, because of the relatively small magnitude of the average mass loss values. 
5.2 Effects of Temperature-Moisture and UV-Intermittent Moisture cycling

\subsubsection{Temperąture-Moisture Cycling}

After having been subjected to hot-cold cycling, mild freeze-thaw cycling, and severe freeze-thaw cycling, the treated specimens had no visible evidence of cracking or separation of the treated zone from the untreated zone. The specimens were examined under a light microscope at a magnification of 14 to 30 on their exterior surfaces and on their interior surfaces (obtained by sawing the specimens). Using similar examinations, no cracking was found in the untreated specimens.

The average mass loss per specimen, based on weighings before and after all cycling was completed, was $7 \mathrm{~g}$ for the treated specimens and $11 \mathrm{~g}$ for the untreated specimens. These mass losses, compared with the original masses of the specimens, were not considered to be substantial or important. Due to the friability of the stone, at least part of the mass losses were attributed to handling.

After all cycling testing had been completed and the specimens had air dried, water still beaded on the surface of the treated zone, which was $3.5 \mathrm{~cm}$ deep.

\subsubsection{UV-Intermittent Moisture Cycling}

After having been exposed to UV light and intermittent moisture, the specimens had no visible evidence of surface cracking on their exposed surfaces. In addition, there was no discernible color difference between the treated and untreated exposed surfaces. 
The mass loss per specimen, based on weighings before and after all cycling was completed, was 3 to $4 \mathrm{~g}$ for both the treated and untreated specimens. These mass losses, when compared to the original masses of the specimens, were not considered to be substantial or important.

After being exposed to the UV-moisture cycles, the treated surfaces still beaded water.

\subsection{Water Absorption}

The average water absorption value for the 6 untreated stone specimens was 11.2 percent, substantially exceeding the value for the 6 treated samples, of 6.7 percent. The corresponding coefficient of variation values for the untreated and treated specimens were 7.0 and 5.8 percent, respectively. The difference in the average values was statistically significant ${ }^{i}$.

\section{SUMMARY AND CONCLUSIONS}

\subsection{Summary}

At the request of the National Park Service, one surface treatment, which was intended to improve the erosion resistance of coquina stone at the Castillo de San Marcos, was evaluated. The commercially-available stone surface treatment was claimed to contain both consolidating and water-repellent agents. Limited, short-term tests were conducted and were intended to simulate two types of erosion and to identify any severe degradation problems. Erosion caused by (i) mechanical abrasion from strokes with a

1 The "t" value was 12.8. Therefore, the difference between the average absorption values for the treated and untreated specimens was considered statistically significant. See footnote "f". 
steel brush and, (ii) a thin stream of water flow were investigated in the laboratory in different stone orientations. The erosion was measured by the mass loss of treated coquina stone compared with that of untreated coquina stone using sawn surfaces. Hot-cold cycling, freeze-thaw cycling, and UVintermittent moisture exposure tests were conducted.

\subsection{Conclusions}

1. The mass loss resulting from steel-bristled brush strokes on dry stone was significantly less for the treated than for the untreated stone specimens in one (No. 1, figure 3) of the three stone orientations investigated. There was not a statistically significant difference in the mass losses between treated and untreated specimens in the other two stone orientations investigated.

2. The mass loss resulting from water flow on the stone was significantly less for the treated than for the untreated stone in both of the stone orientations investigated for water-flow volumes of about $4100 \mathrm{~L}$. At water-flow volumes from 4100 to 5650 L, however, there was not a significant difference in mass loss between the treated and untreated stone in both stone orientations.

3. Based on the results of the limited, short-term tests, it appeared that there were no severe degradation effects (e.g., cracking in coquina) caused by the treatment. A slight darkening in some specimens with sawn surfaces was discerned.

4. From the limited, short term tests conducted, it appears that the treatment: (i) has the potential in some cases (see 1 . and 2. above) to improve the erosion resistance of coquina stone, and (ii) potentially, at least in the short term, should not cause 
detrimental effects in the coquina (see 3. above), with the exception of a slight darkening in some specimens with sawn surfaces.

\section{RECOMMENDATIONS}

Based on the results from the limited and short-term tests, it is recommended that the treatment be applied to several trial areas at the Castillo de San Marcos. The trial areas should be locations where erosion due to water flow (e.g., roof scuppers) or mechanical abrasion (e.g., by rubbing, brushing, walking, or picking) or both are occurring. The bedding-plane orientation of the coquina stone relative to the erosion resistance (see Chapter 5) should be taken into account when selecting the trial areas. The trial areas should be periodically observed and the erosion documented quantitatively, if possible, over an extended time period (e.g., 5 to 10 years). This documentation would provide an indication of the durability and performance with time of the treated coquina stone.

Proper procedures for preparing the coquina stone trial areas should be developed, including the determination of the degree of cleanness and dryness required prior to application of the treatment at the Castillo de San Marcos. Also, the proper application rate (loading) of the treatment at the Castillo de San Marcos should be determined. Application rate refers to the required mass or volume of treatment (uncured liquid or remaining solids after curing) applied per unit surface area of stone. Appropriate safety measures should be followed. Field application procedures and safety measures should be discussed with the treatment supplier. Field tests may be needed to establish proper preparation procedures and an appropriate application rate. The variability in coquina stone, including its density, should be considered in establishing proper preparation procedures and an appropriate application rate. 
8. REFERENCES

1. Schmidt, W. et. al., "Report of Investigation No. 88, The Limestone, Dolomite and Coquina Resources of Florida," Bureau of Geology, Florida Department of Natural Resources, Tallahassee FL, 1979.

2. Knab, L. I. and Clifton, J. R., "Mechanical and Physical Properties of Coquina stone from the Castillo de San Marcos National Monument," NBSIR 88-3714, National Institute of Standards and Technology, Gaithersburg, MD, January, 1988 .

3. Rossiter, W. J., Jr. and Mathey R. G., "Effect of Insulation on the Surface Temperature of Roof Membranes," NBSIR 76-987, National Institute of Standards and Technology, Gaithersburg, MD, February, 1976.

4. "Climatography of the United States No. 20, Climate of Saint Augustine, Florida," NOAA, National climatic Center, Asheville, N. C., August, 1976.

5. ASTM, Standard Practice for operating Light-Exposure Apparatus (Xenon-ArC Type) With and Without Water for Exposure of Nonmetallic Materials ASTM G 26-88, ASTM, Philadelphia, PA, 1989.

6. ASTM, Standard Test Methods for Absorption and Bulk Specific Gravity of Natural Building stone, ASTM C 97-83 (1988), ASTM, Philadelphia, PA, 1989.

7. Natrella, M. G., "Experimental Statistics," Handbook 91, National Institute of Standards and Technology, Gaithersburg, MD, 1966.

\section{ACKNOWLEDGEMENTS}

This investigation was conducted for the National Park Service, under the direction of Mr. Billy G. Garrett. The assistance of Mssrs. Billy G. Garrett and Frederick D. Shott of the NPS are gratefully acknowledged. The authors also wish to thank their NIST colleagues: Mr. Robert G. Mathey and Dr. Geoffrey J. Frohnsdorff for their helpful review comments and Dr. James $J$. Filliben for his statistical consultation. Finally, Ms. Denise L. Herbert is acknowledged for her aid in the preparation of the manuscript. 
Table 1. Mass loss results for mechanical abrasion tests.

\begin{tabular}{|c|c|c|c|c|c|c|c|}
\hline Specimen & Treated & $\begin{array}{l}\text { Stone } \\
\text { Orientation (Fig. 3) }\end{array}$ & $\begin{array}{l}\text { Cycles } \\
\text { Applied }\end{array}$ & $\begin{array}{l}\text { Mass Loss }{ }^{a} \\
\text { Individual }\end{array}$ & $\begin{array}{l}(\mathrm{g} / 10 \\
\text { Avg. }\end{array}$ & $\begin{array}{l}\text { Do cyc } \\
\text { s.d. }\end{array}$ & $\begin{array}{l}\text { les) } \\
C V(\%)\end{array}$ \\
\hline A & No & 1 & 2500 & 7.7 & \multirow{6}{*}{7.4} & \multirow{6}{*}{1.3} & \multirow{6}{*}{17.} \\
\hline B2 & No & 1 & 2500 & 6.0 & & & \\
\hline \multirow[t]{2}{*}{ C } & No & 1 & 2500 & 8.4 & & & \\
\hline & & & & & & & \\
\hline D & Yes & 1 & 2500 & 1.8 & & & \\
\hline$E$ & Yes & 1 & 2500 & 1.2 & & & \\
\hline \multirow[t]{2}{*}{$\mathrm{F}$} & Yes & 1 & 2500 & 1.6 & \multirow[b]{2}{*}{1.5} & \multirow[b]{2}{*}{0.28} & \multirow[b]{2}{*}{19.} \\
\hline & & & & & & & \\
\hline G & No & 2 & 5500 & 1.0 & \multirow{6}{*}{0.63} & \multirow{6}{*}{0.34} & \multirow{6}{*}{54.} \\
\hline $\mathrm{H}$ & No & 2 & 5500 & 0.38 & & & \\
\hline \multirow[t]{2}{*}{$I$} & No & 2 & 5500 & 0.49 & & & \\
\hline & & & & & & & \\
\hline $\mathrm{J}$ & Yes & 2 & 5500 & 0.51 & & & \\
\hline $\mathrm{K}$ & Yes & 2 & 5700 & 0.28 & & & \\
\hline \multirow[t]{2}{*}{ L } & Yes & 2 & 5500 & 0.15 & \multirow[b]{2}{*}{0.31} & \multirow{2}{*}{0.18} & \multirow[b]{2}{*}{59.} \\
\hline & & & & & & & \\
\hline
\end{tabular}

\begin{tabular}{|c|c|c|c|c|c|c|c|}
\hline $\mathrm{M}$ & No & 3 & 5000 & 1.7 & & & \\
\hline$N^{b}$ & No & 3 & $1500^{b}$ & $8.4^{b}$ & & & \\
\hline N1 & No & 3 & 5000 & 0.60 & & & \\
\hline \multirow[t]{2}{*}{0} & No & 3 & 5000 & 0.44 & & & \\
\hline & & & & & 0.93 & 0.71 & 76. \\
\hline$P$ & Yes & 3 & 5000 & 0.68 & & & \\
\hline$Q$ & Yes & 3 & 5000 & 0.22 & & & \\
\hline \multirow[t]{2}{*}{$\mathrm{R}$} & Yes & 3 & 5000 & 1.0 & & & \\
\hline & & & & & 0.65 & 0.41 & 64. \\
\hline
\end{tabular}

$a_{\text {Avg. }}=$ average $;$ s.d. = standard deviation;

$C V(\%)=$ coefficient of variation $=($ s.d./Avg.) $\times 100$

bspecimen became deeply rutted after 1500 cycles; no additional cycles were applied to specimen; specimen was considered an outlier and was excluded from Avg., S.d., CV, and $t$ (Section 5.1.1) values. 
Table 2. Mass Loss of Water-Flow Specimens

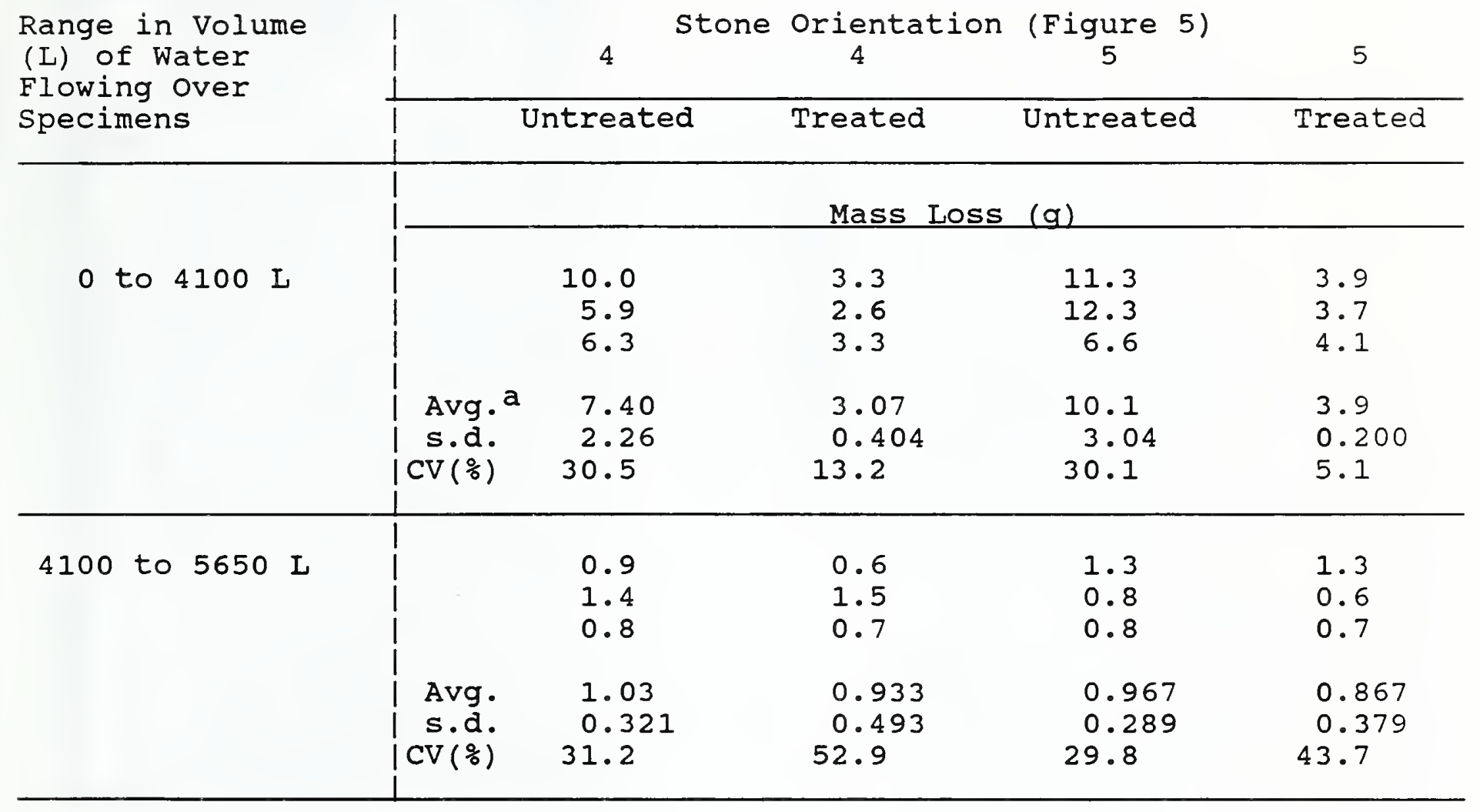

$\mathrm{a}_{\mathrm{Avg}}=$ average; $\mathrm{s.d.}=$ standard deviation; $\mathrm{CV}(\%)=(\mathrm{s} \cdot \mathrm{d} \cdot \mathrm{A} / \mathrm{Avg} \cdot) \mathrm{x} 100 \mathrm{based}$ on the three replications listed. 

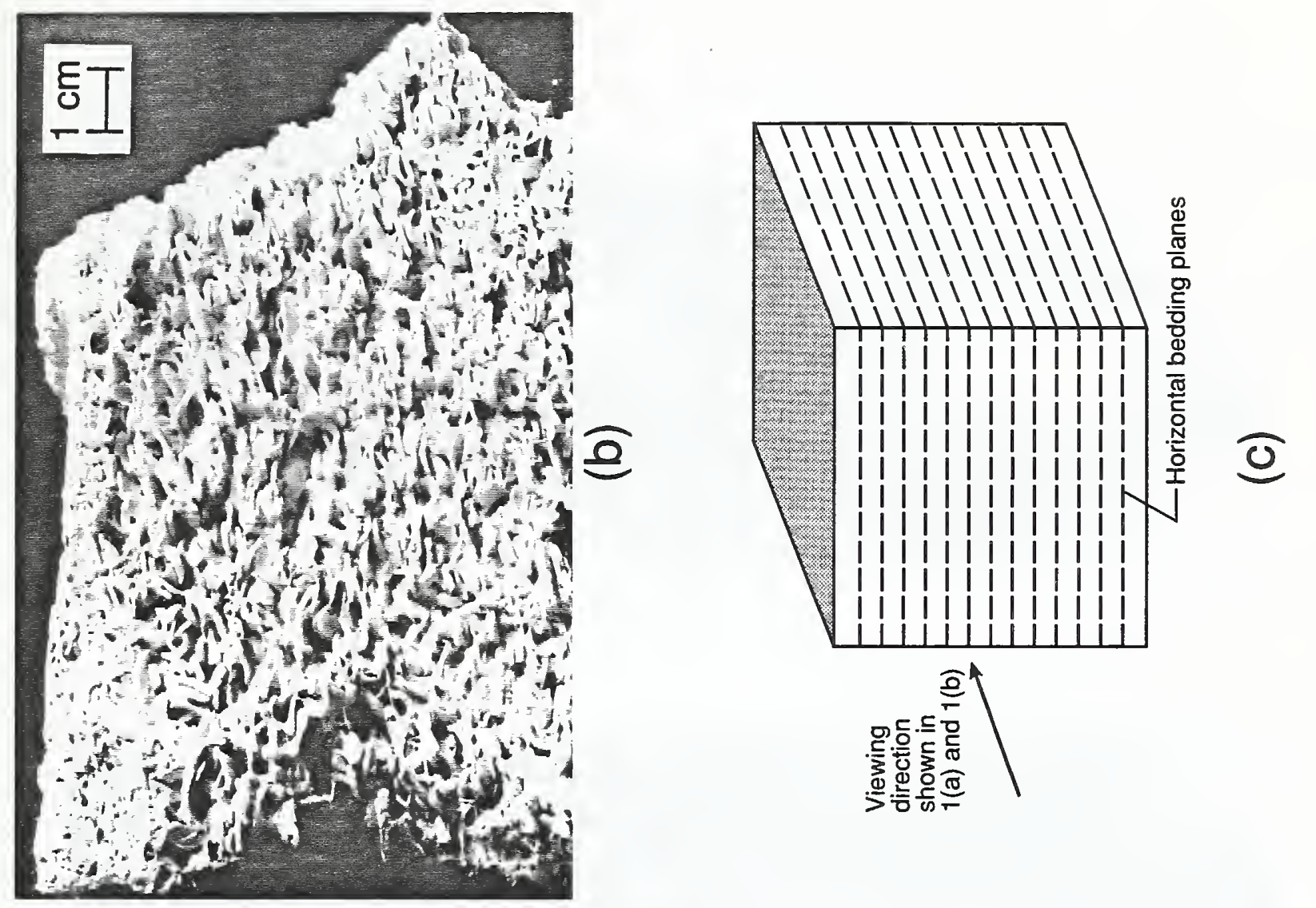

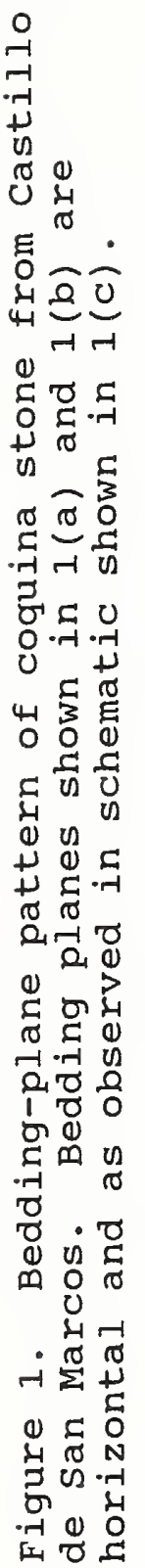

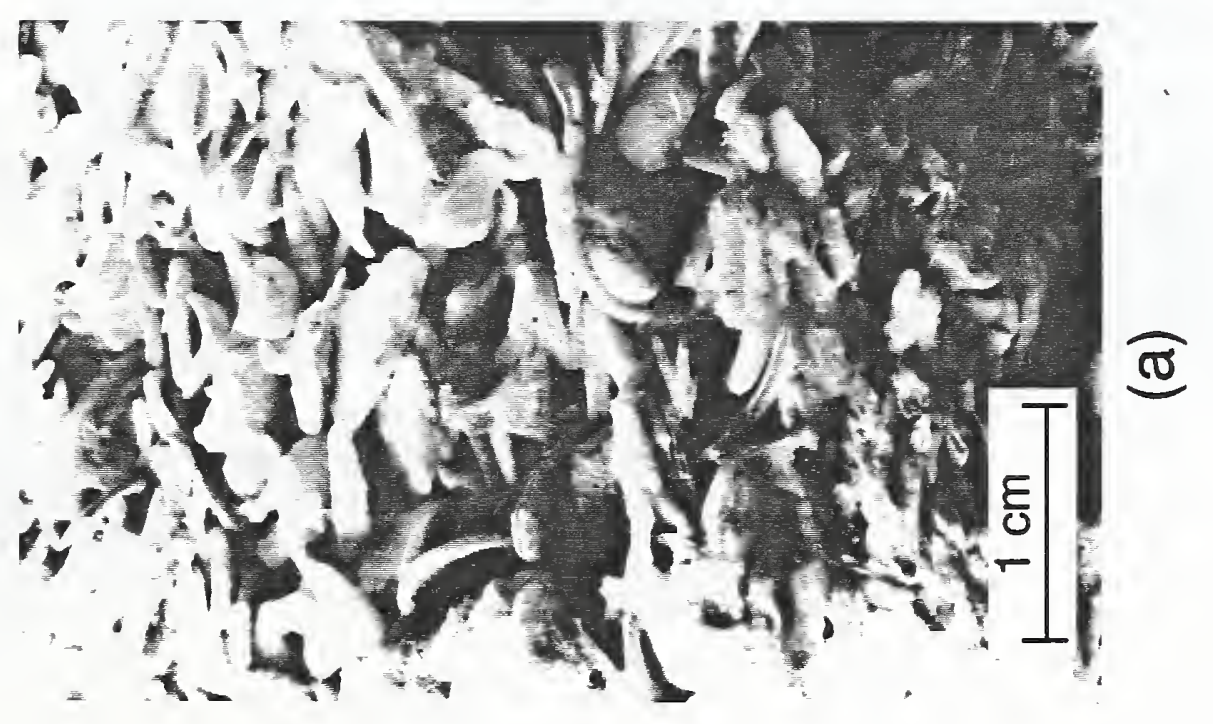





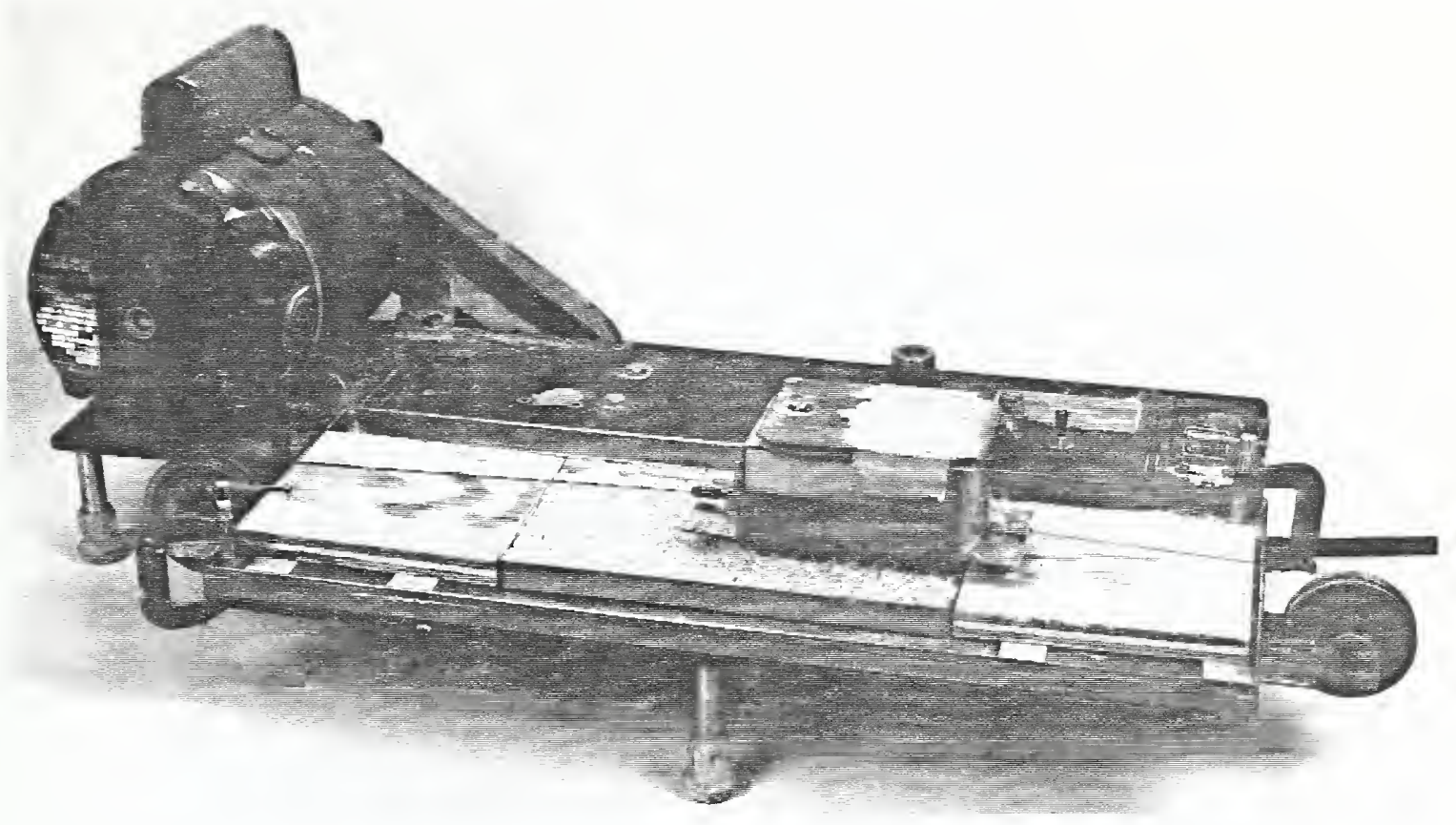

(a)

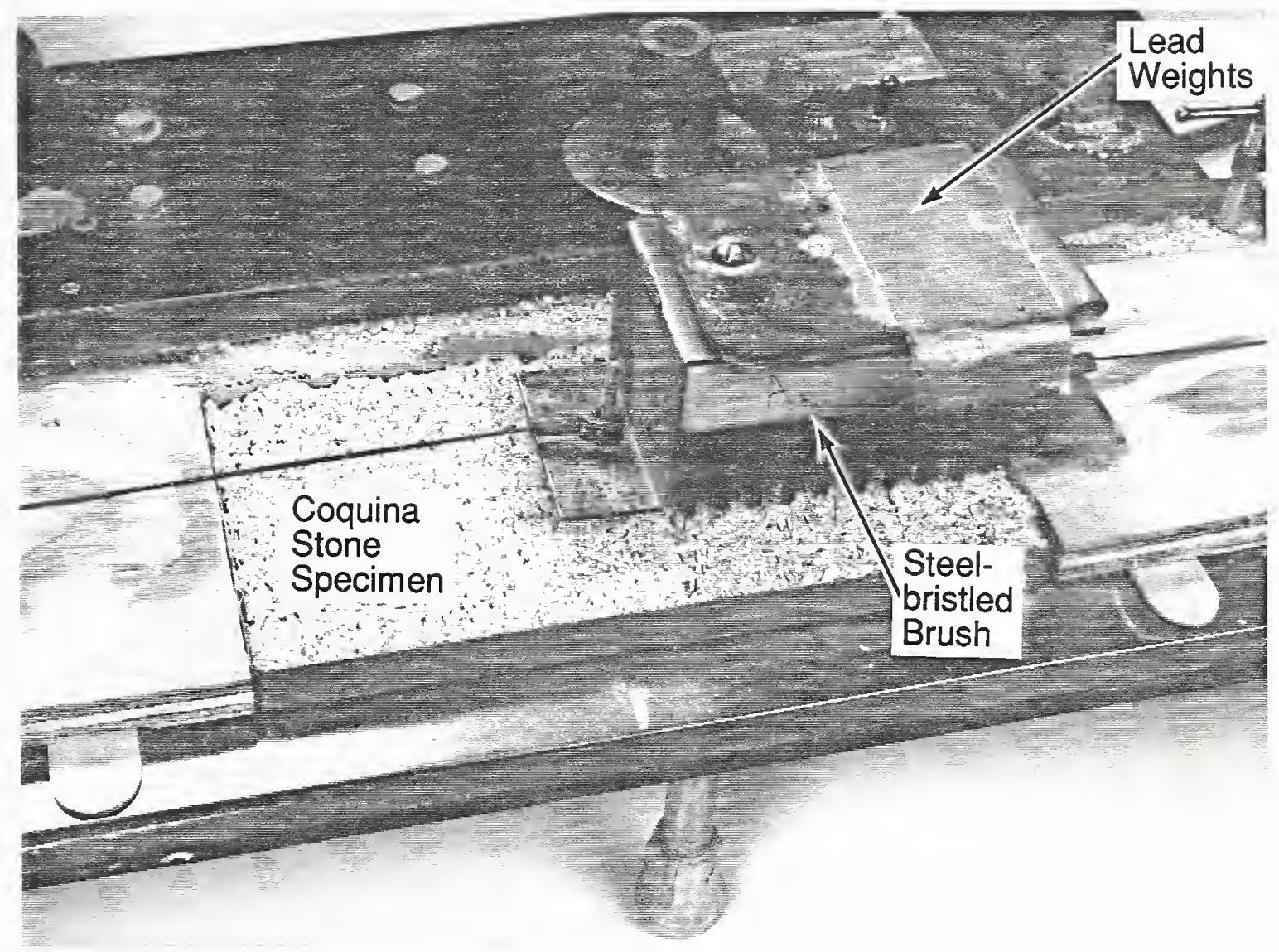

(b)

Figure 2. (a) Overall view of mechanical-abrasion test apparatus, (b) Close up view showing the specimen and the steelbristled brush. 


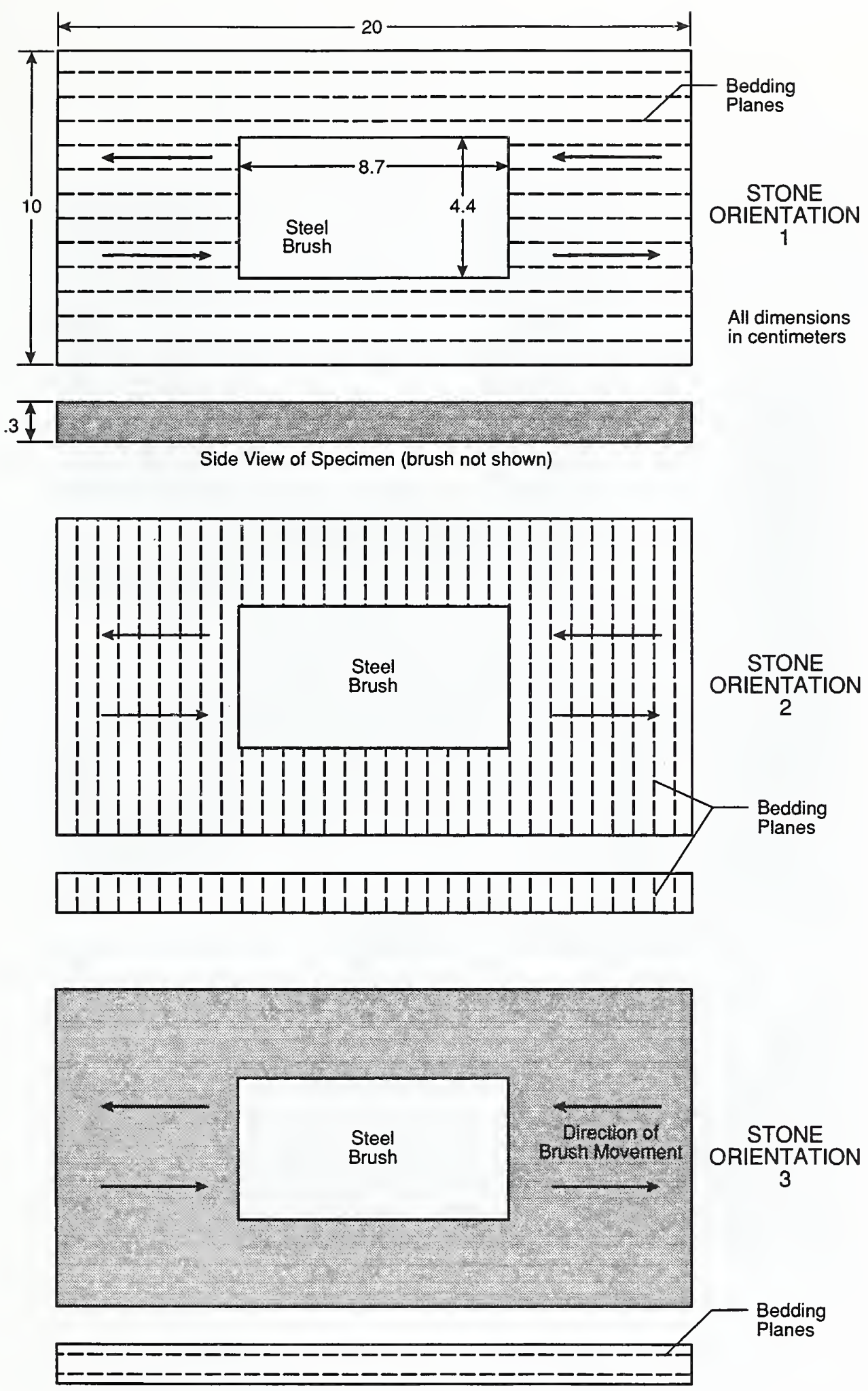

Figure 3. Stone orientations for mechanical abrasion testing. The bedding planes shown are schematic; figure 1 shows an example of actual bedding planes. Steel brush bristles moved from left to right and from right to left. 



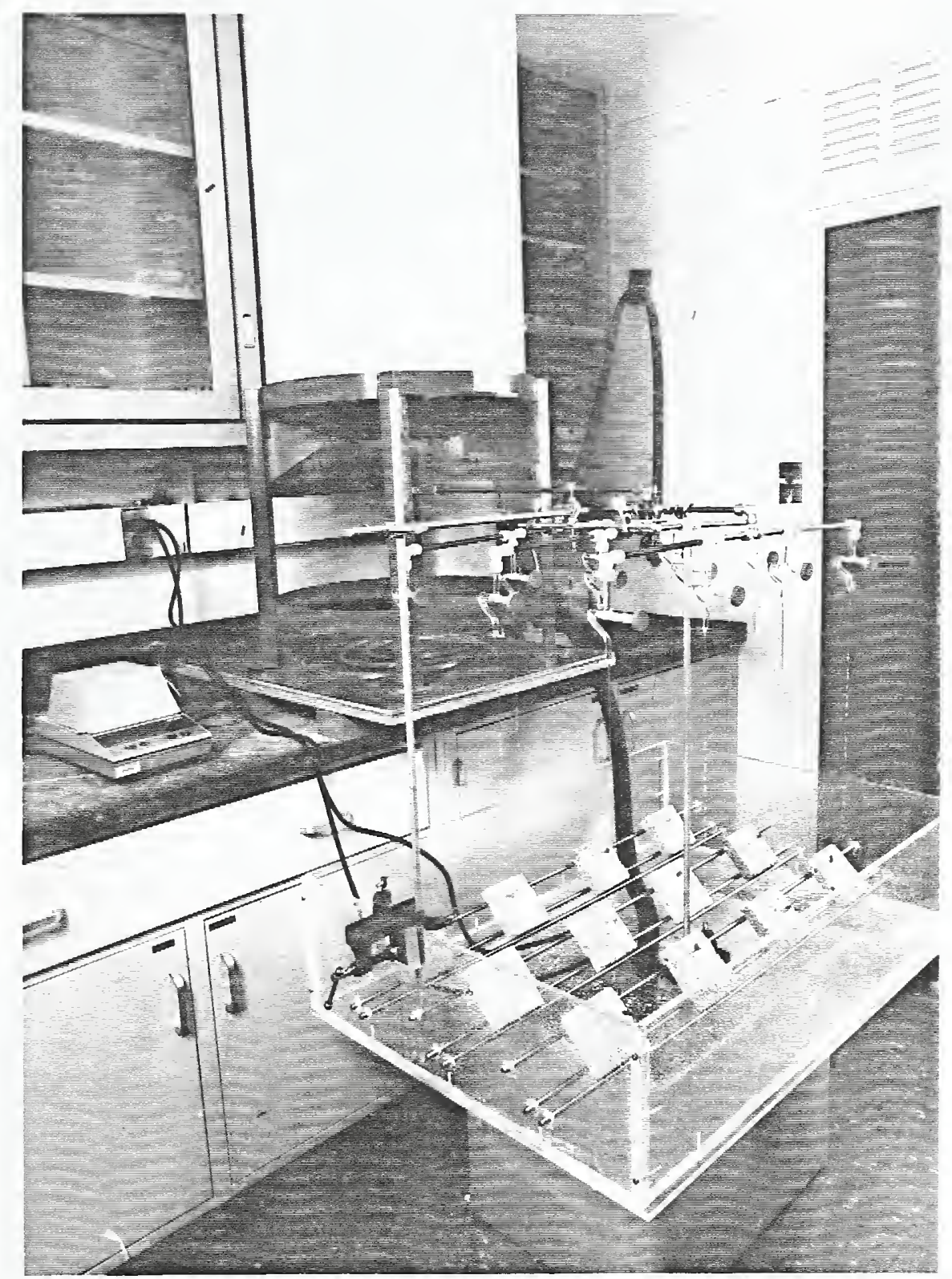

Figure 4. (a) Overall view of water-flow erosion test setup. 


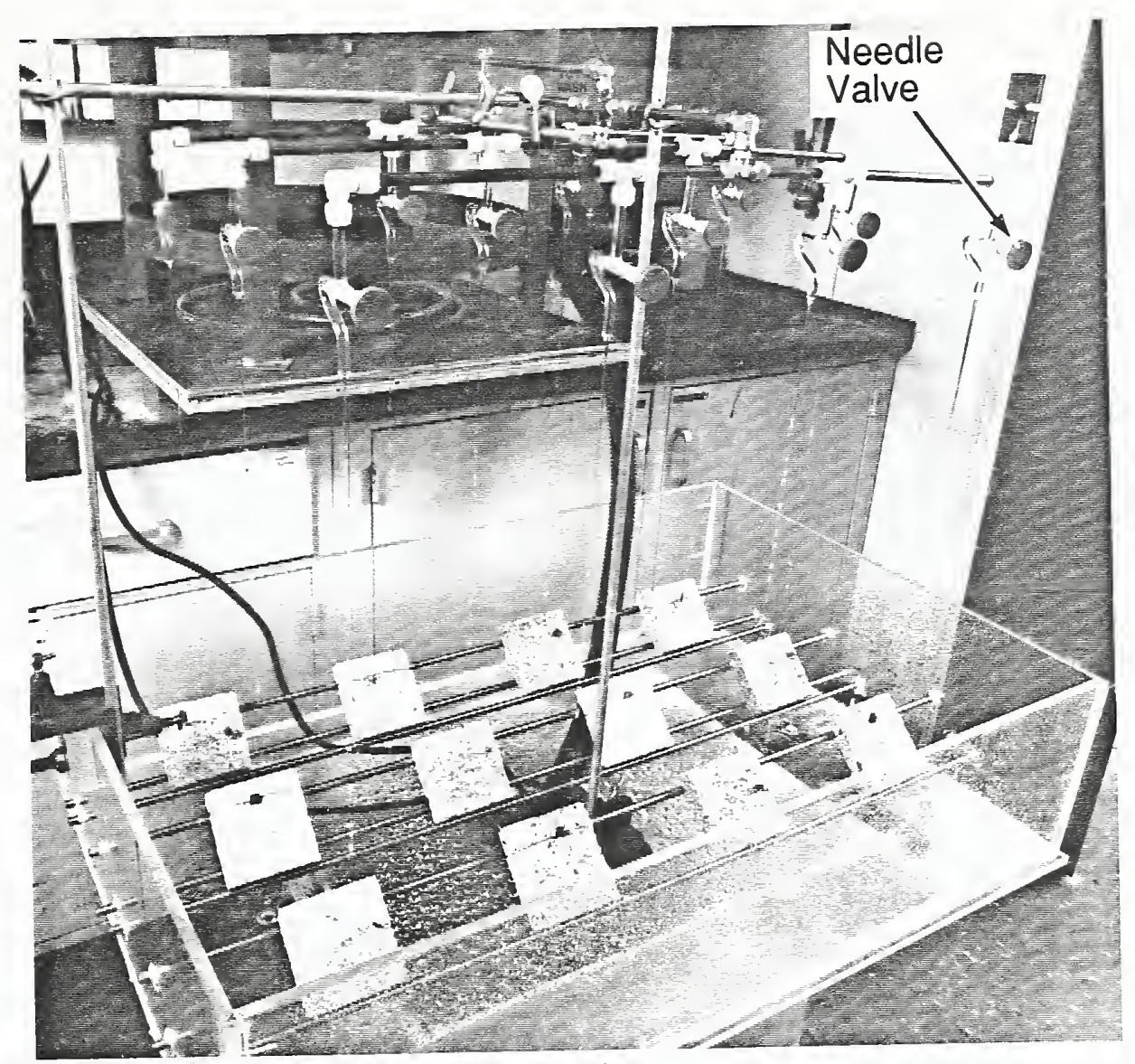

(b)

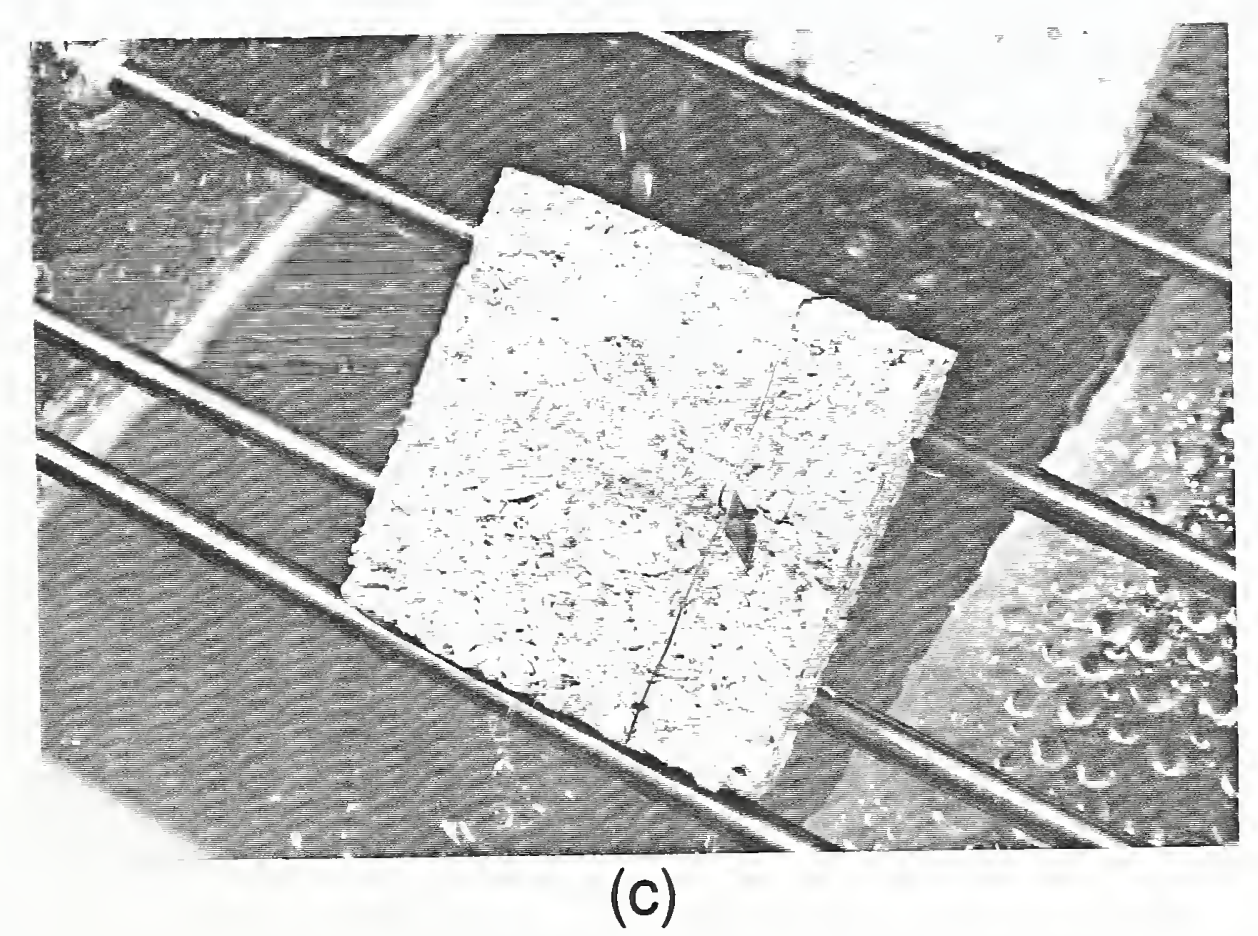

Figure 4. (b) View of frame that held and positioned the stone and needle valves, and (c) View of the stone positioned at a $45^{\circ}$ angle. 

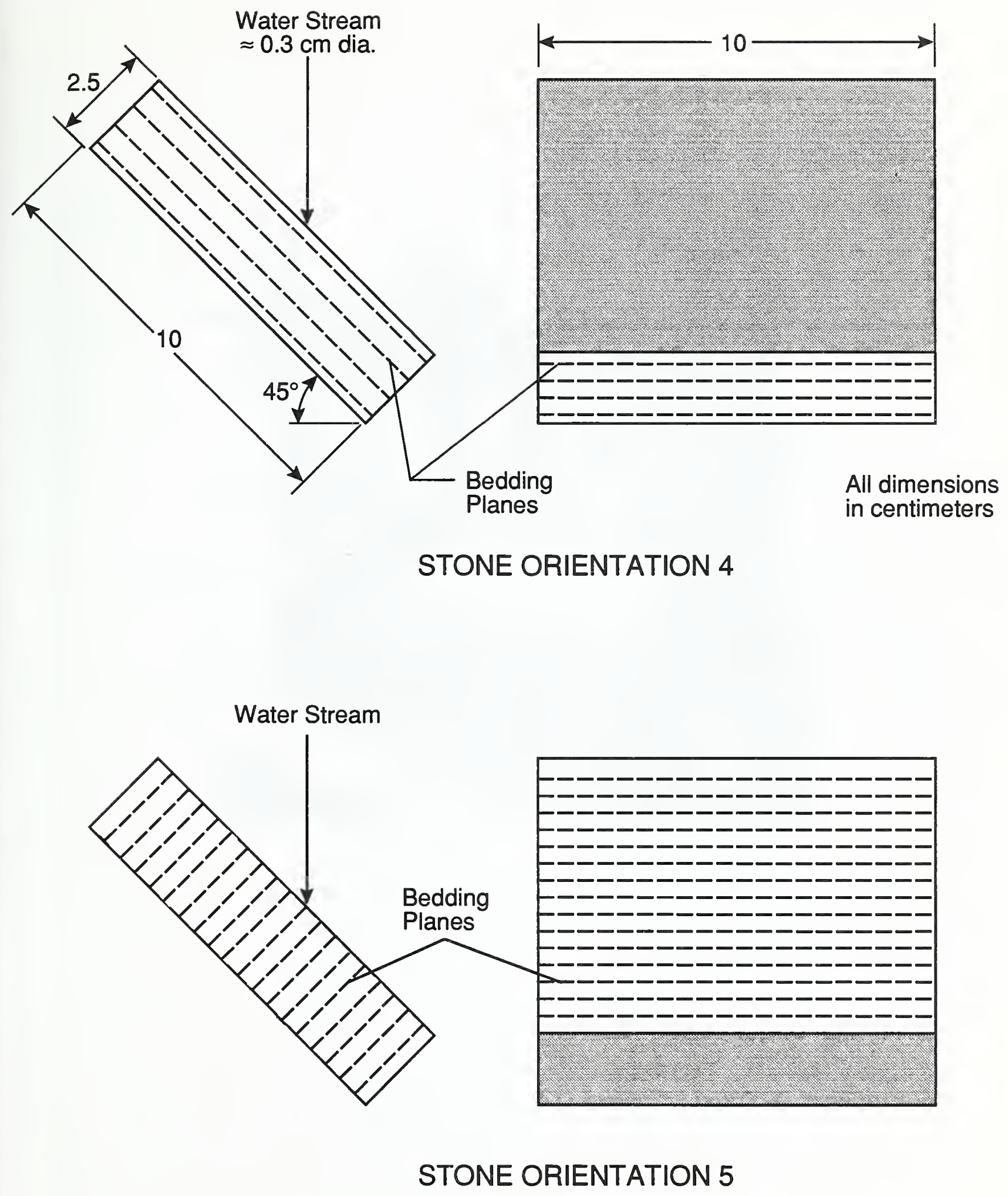

Figure 5. Stone orientations of coquina stone specimens used for water-flow testing. 



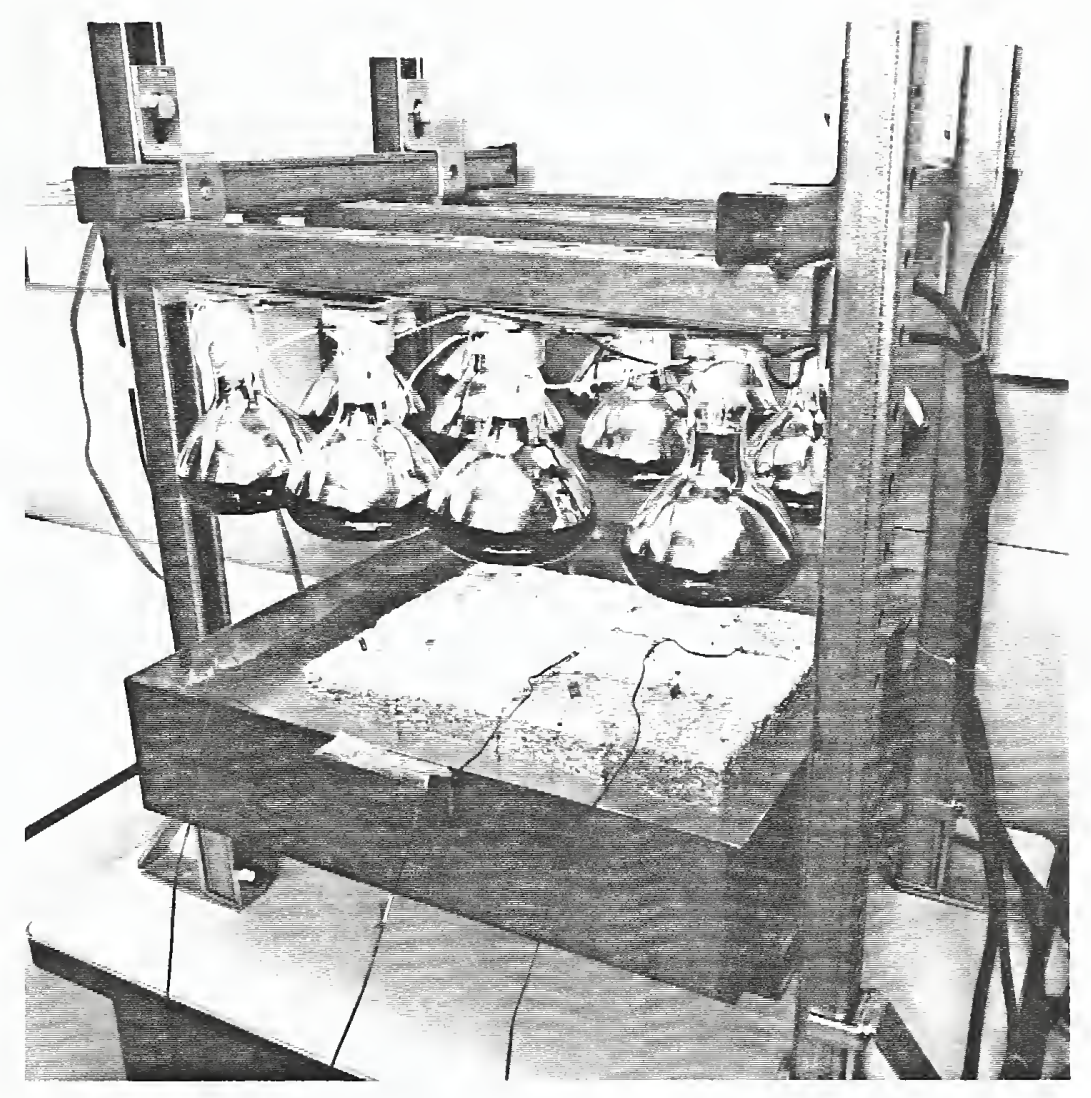

Figure 6. Test setup for hot-cold moisture cycling, showing lamps used to apply heat to test cubes. 



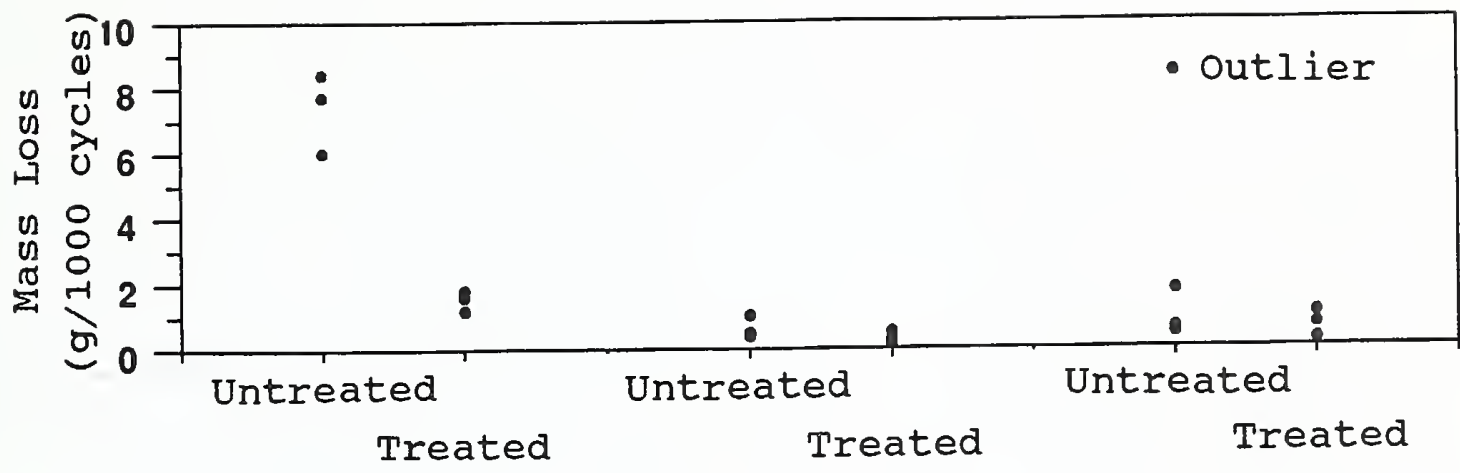

Stone

Orientation

(figure 3)

11

$2 \quad 2$

3

3

Figure 7. Mass loss (in g/1000 cycles, table 1) for untreated and treated specimens in each of the three stone orientations shown in figure 3 for mechanical abrasion tests.
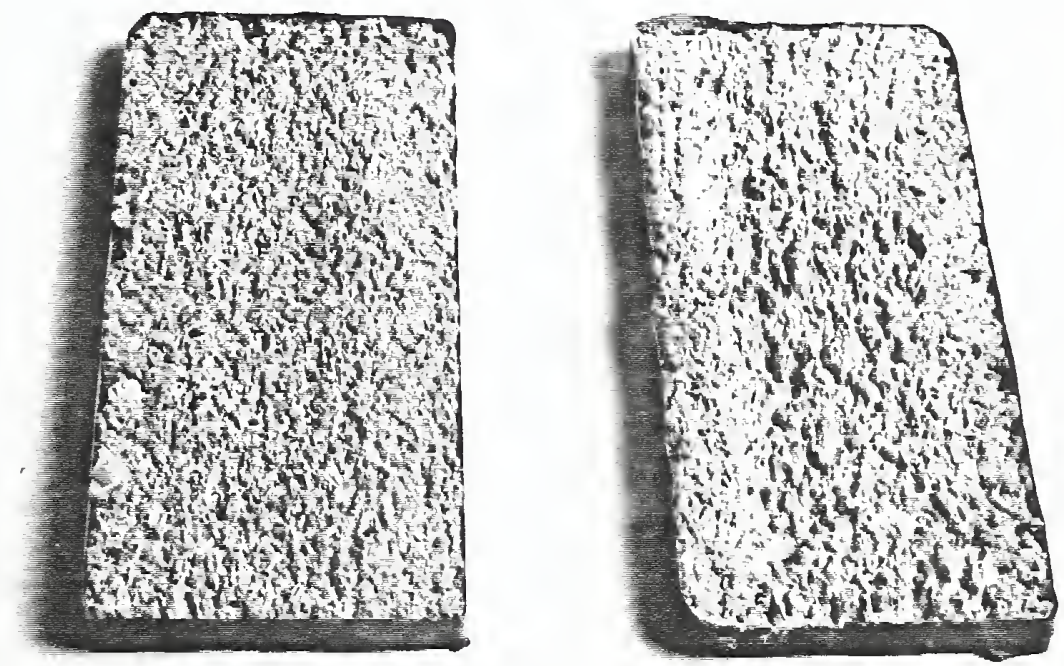

Figure 8. Two specimens after being mechanically abraded for 2500 cycles in stone orientation 1. Specimen $E$ on the left was treated and had a mass loss of $3.0 \mathrm{~g}$. Specimen $A$ on the right was untreated and had a mass loss of $19.3 \mathrm{~g}$ (table 1 ). 



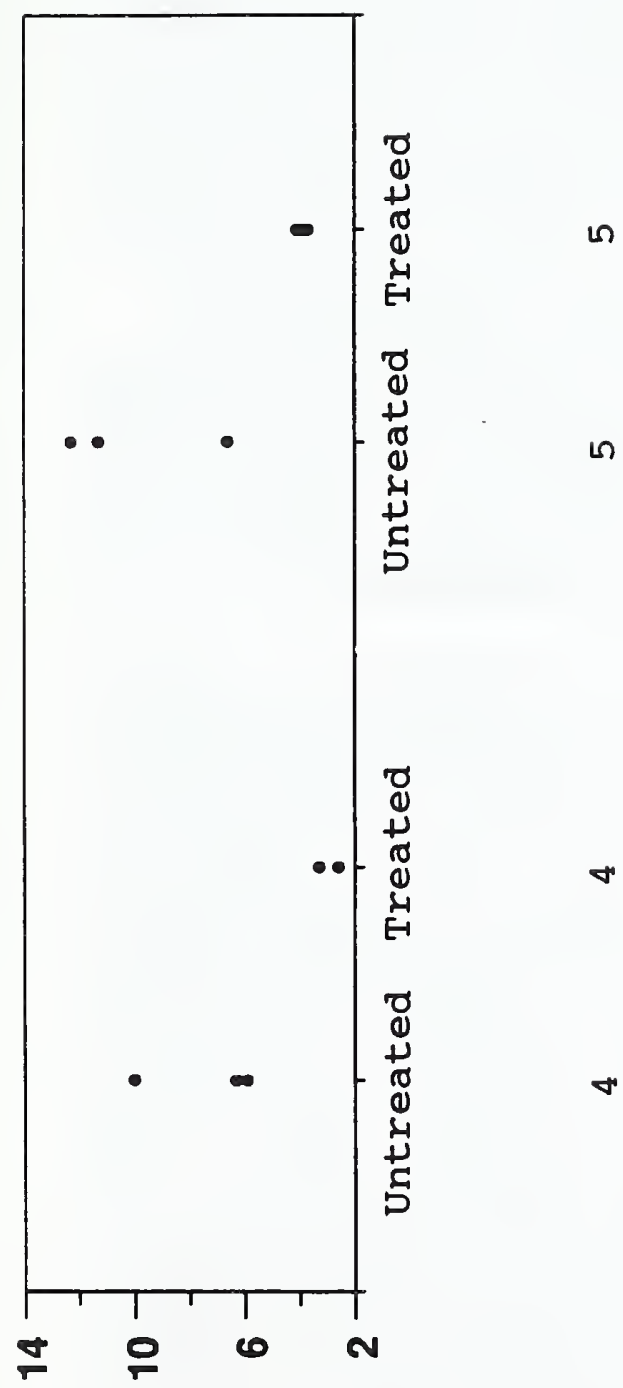

น

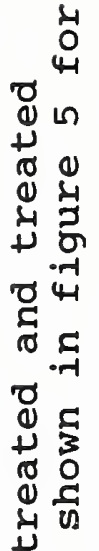

$n$

รี

क्ष

幽芹

จ

0. प्र

ด

$+0$

कi⿱ 口甘

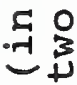

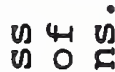

०

뎡

U)

(1) 0

$\sum$ 的

- 3

$\sigma:$

(1) है

4. त 4

ว 0

Oा

엄

- 120

(⿻)

1)

(1) ह

०.न-न

$+44$

की 0 

if

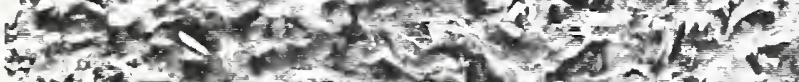

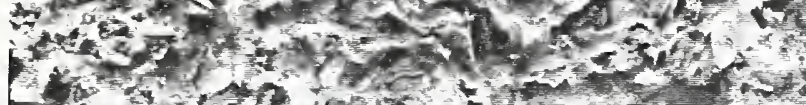

$-x^{2}+2,3, y$

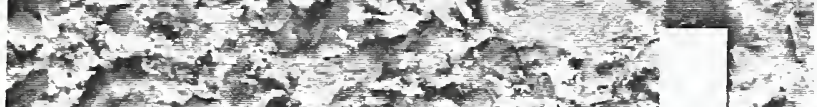

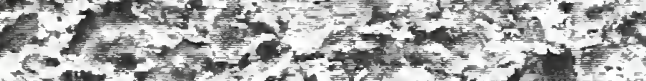

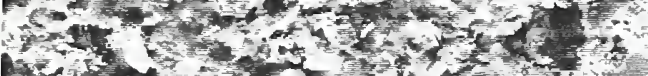

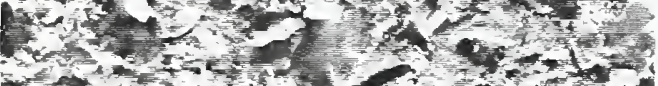

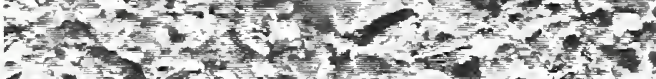

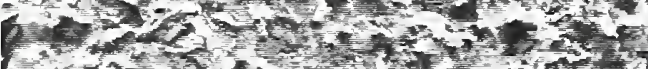

b.t.

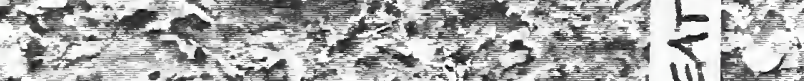

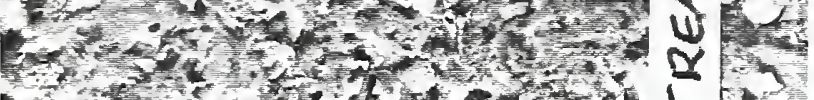

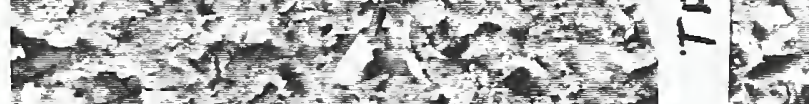

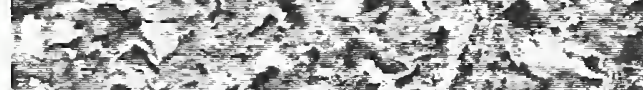

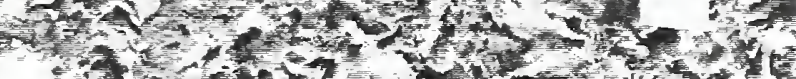

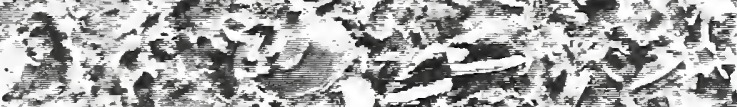
1.t. 1.

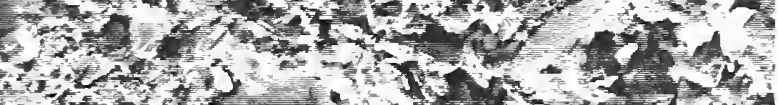

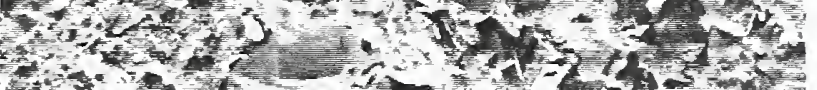

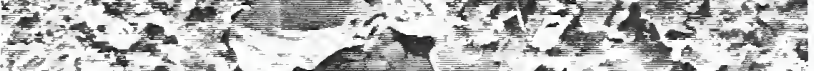

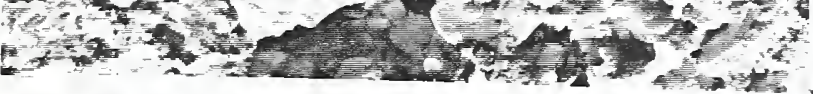

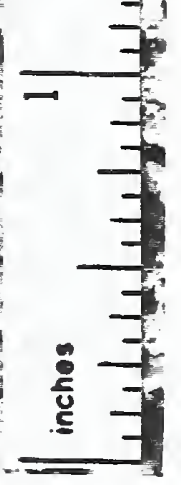

(1) 0

正

+ ل्न

य

등

- U

थ

ฮิ

E 0

- +14

0 \% 0

$00+$

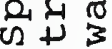
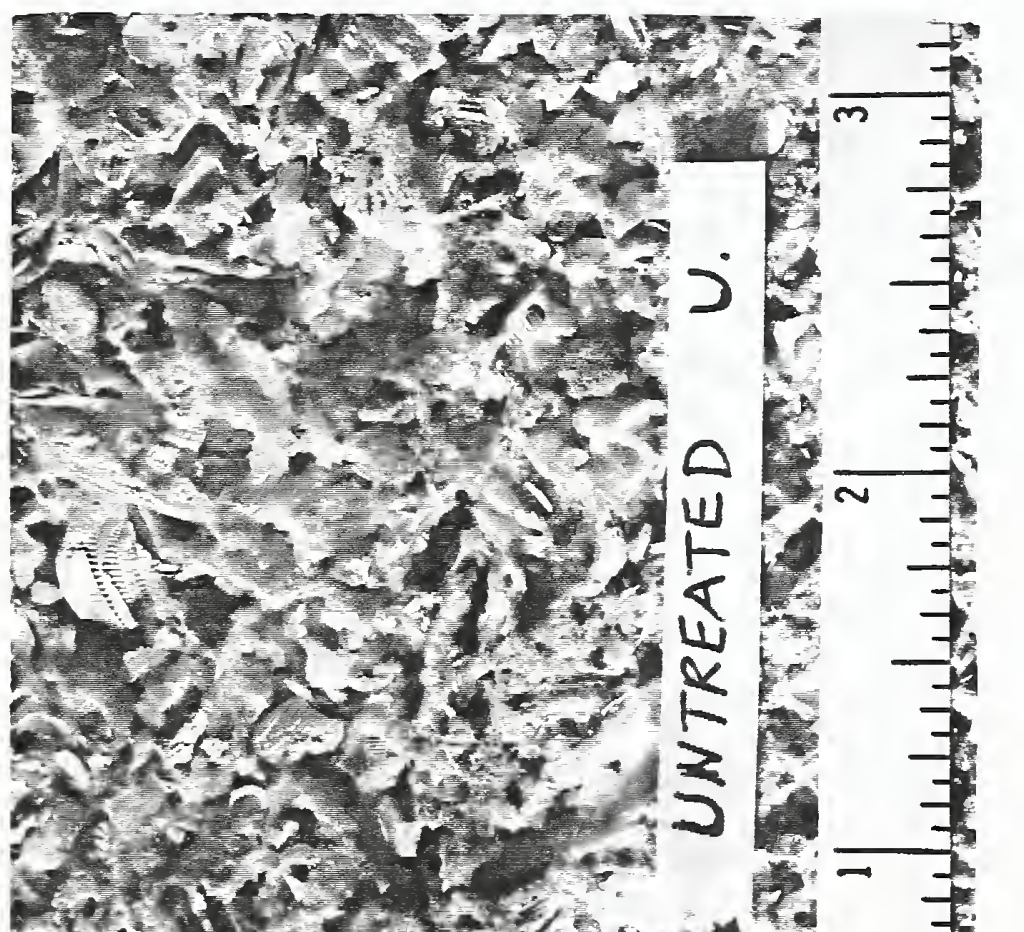

(

竞

\% 0

0 .

出

㝳告

०

4

50

$-1$

$+5$.

당 웅

可

$0+$

(1) 5

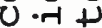

舤

4

כ) 4

is 50

(1)

兘的

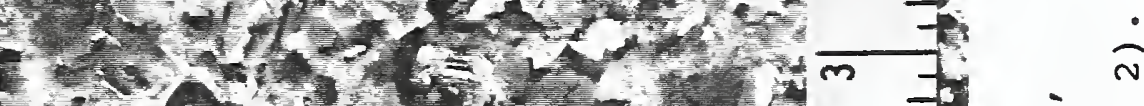

เก

ข

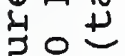

ㅎํ으

- 6 or

4 L

4?

$+00$

工

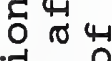

-

$+\frac{1}{3}$

ช

ᄃ

o on

- 1

4ᄃ द U

○。 n

(1) 1

ธूँ

牙

U

S.

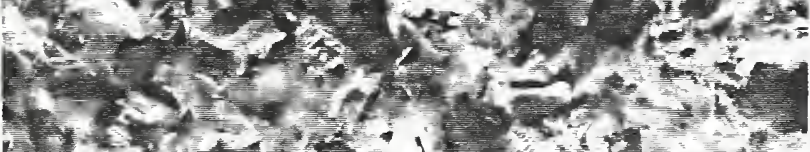

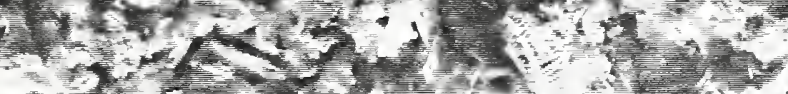

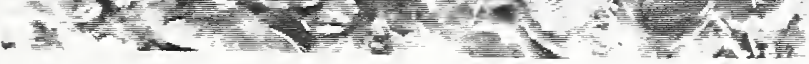

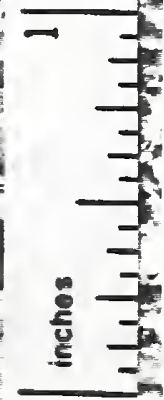

• 3

ठ

5 0

$0+4$

E

o \&

(1) +

도 


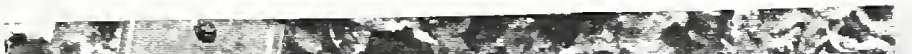

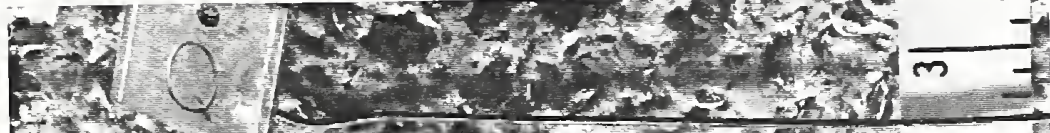

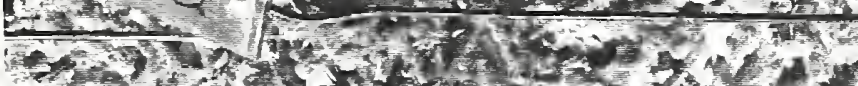

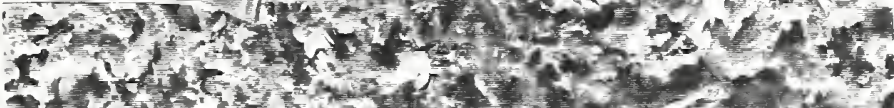

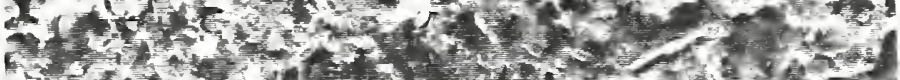

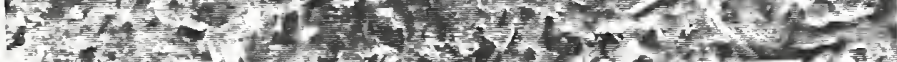

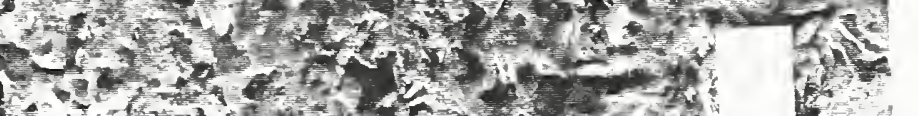

i.

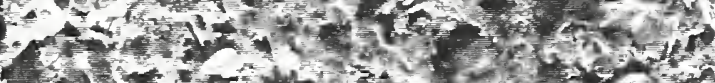

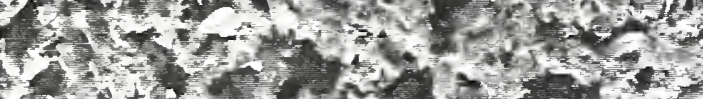

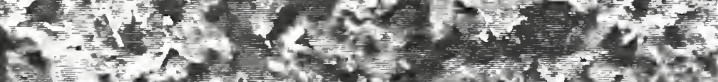
43 s.

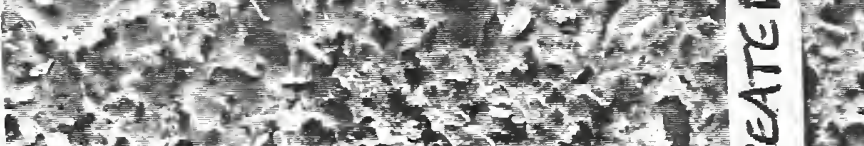

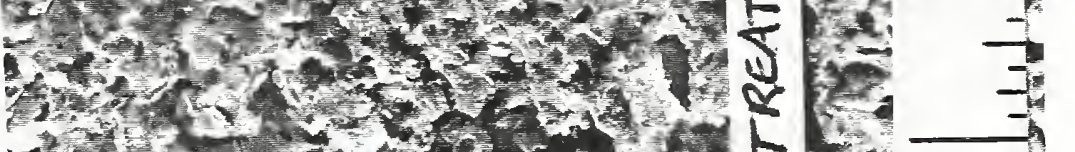

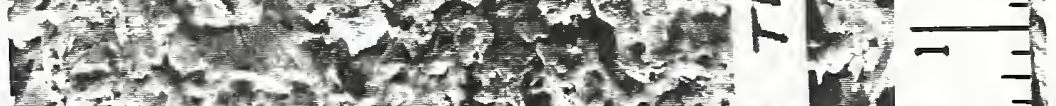

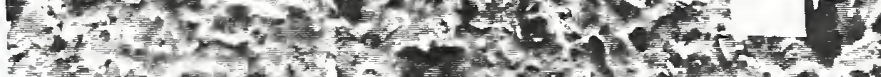

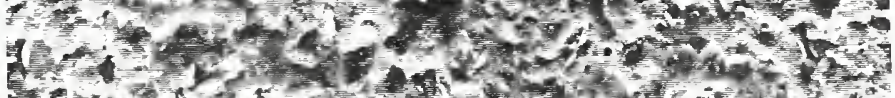

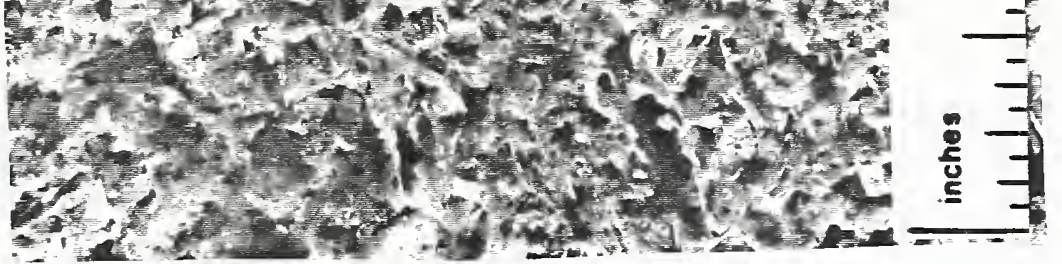

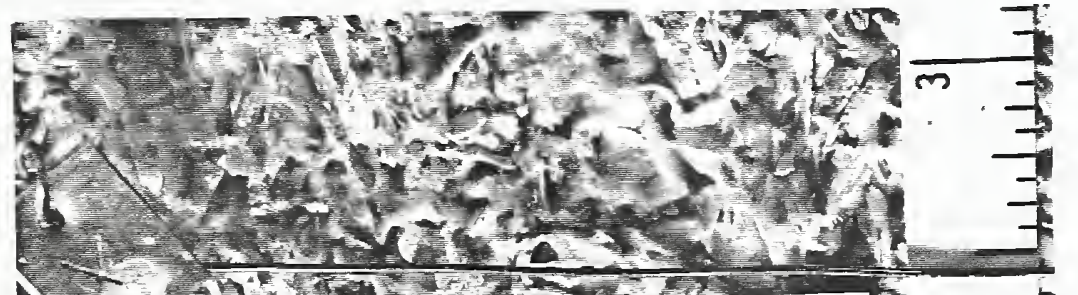

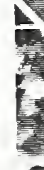

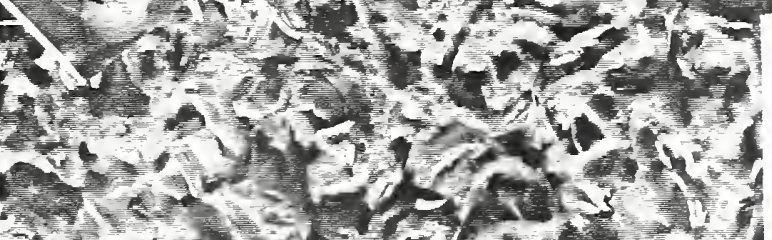

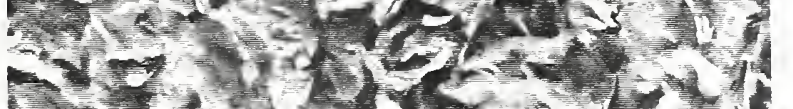

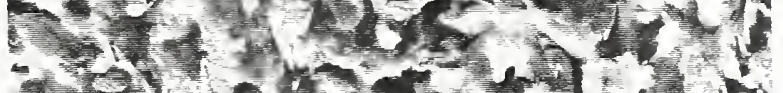

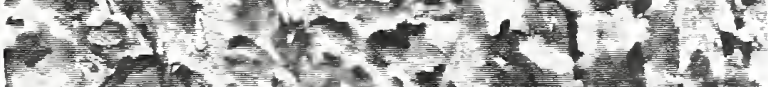

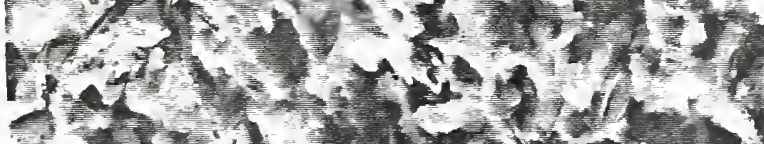

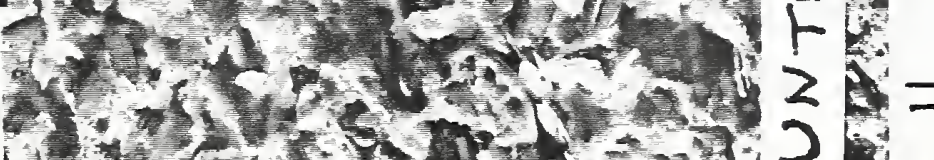

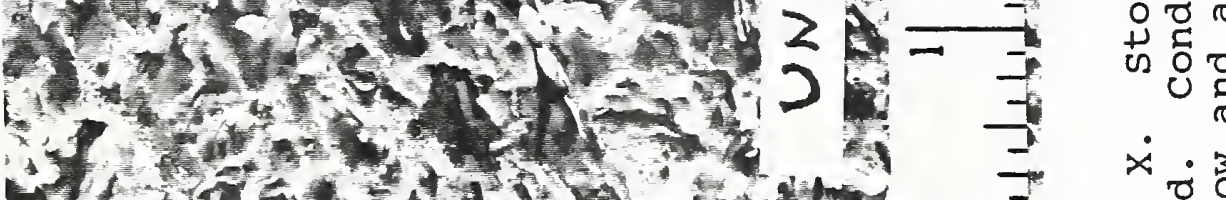

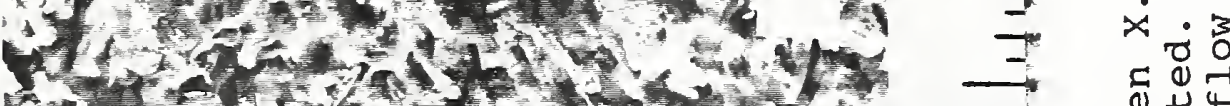

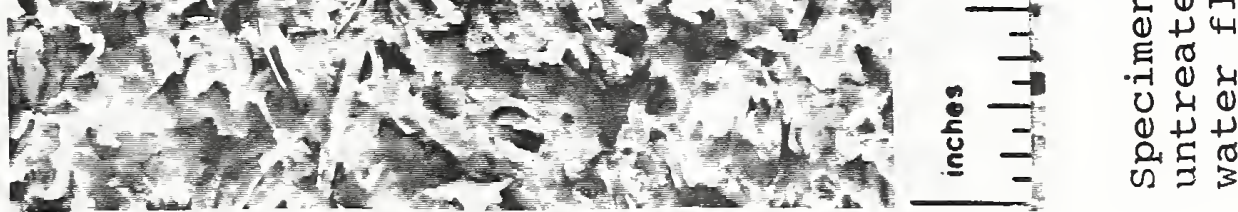
- $\overparen{N}$ (n) 1 (1) 0 응 हुㅍ - 10 $-6$ เ 4 है⿴囗十丁 - 40 r $n$ $+\frac{1}{3}$ U (1) 0 다 प्र थ - 5 元 (1) 0 E 대 प्र. บ . 0 03 두혀 E 0 $-7+2$ 0 r 0 (1) $0+$ क्ष

240

in 0 .

(4)

그은 - नि in o 4 in

- 6 (ก) $\mathrm{N}$

c 4

인

出 5

+0 u

C) 兵 0

- -1

प् 5 U

.न

$0+E$

대유

$+\mathrm{C}$ $0 \mathrm{E}$

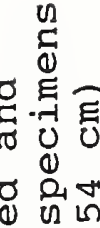
$+1$ ช $4 N$ (1) ᄃ 니 II पू 0 c ㄷํㅇ + 5 ठ․ㄷㅇ 당 $0+$

(1) 5

$0 .-10$

(1) 403 光 04 ज 0 $0+1$ 灷山。 동 $0 .-10$ u 30 - $ᄃ$ 용 हE. ह $x \cup 1$ [व 0 ט त $\delta$ ? -1 0 $+0$

म 01 के - $E$ 元 厌了近 



\section{TITLE AND SUBTITLE}

Evaluation of a Surface Treatment to Improve the Erosion Resistance of Coquina Stone at Castillo de San Marcos

5. AUTHOR(S)

Lawrence I. Knab, James R. Clifton; Nathaniel Waters

6. PERFORMING ORGANIZATION (IF JOINT OR OTHER THAN NIST, SEE INSTRUCTIONS)

U.S. DEPARTMENT OF COMMERCE

NATIONAL INSTITUTE OF STANDARDS AND TECHNOLOGY

GAITHERSBURG, MD 20899

7. CONTRACT/GRANT NUMBER

8. TYPE OF REPORT AND PERIOD COVERED

9. SPONSORING ORGANIZATION NAME AND COMPLETE ADDRESS (STREET, CITY, STATE, ZIP)

National Park Service

Historic Architecture Division

75 Spring St., sw

Atlanta, GA 30303

10. SUPPLEMENTARY NOTES

DOCUMENT DESCRIBES A COMPUTER PROGRAM; SF-185, FIPS SOFTWARE SUMMARY, IS ATTACHED.

11. ABSTRACT (A 200-WORD OR LESS FACTUAL SUMMARY OF MOST SIGNIFICANT INFORMATION. IF DOCUMENT INCLUDES A SIGNIFICANT BIBLIOGRAPHY OR UTERATURE SURVEY, MENTION IT HERE.)

A surface treatment, which was intended to improve the erosion resistance of coquina stone at the Castillo de San Marcos, was evaluated. The commercially-available stone surface treatment was claimed to contain both consolidating and water-repellent agents. Limited, short-term tests intended to simulate two types of erosion and to identify any severe degradation problems were conducted. Erosion of sawn surfaces caused by (i) mechanical abrasion from strokes with a steel brush and, (ii) a thin stream of water flow were investigated in the laboratory in different stone orientations. The erosion resistance, based on mass loss, of the treated stone was compared with that of the untreated stone. The results showed that, for some test conditions, the erosion resistance of the stone was significantly improved by the treatment. For the other test conditions, however, the erosion resistance of the treated and untreated specimens was not significantly different. Hot-cold cycling, freeze-thaw cycling, and ultroviolet light-intermittent moisture exposure tests were conducted and no degradation was observed. In some cases, a slight darkening was discernible on the surface of treated stone with sawn surfaces.

It was recommended that the surface treatment be applied to several trial areas at the Castillo de San Marcos, where erosion due to water flow or mechancial abrasion or both are occurring. The areas should be periodically observed and the erosion documented. quantitatively, if possible, over an extended time period.

12. KEY WORDS (6 TO 12 ENTRIES; ALPHABETICAL ORDER; CAPITALZE ONLY PROPER NAMES; AND SEPARATE KEY WORDS BY SEMICOLONS) Abrasion resistance; Castillo de San Marcos; consolidant; coquina stone; erosion resistance; moisture; preservation; stone surface treatment; temrerature; water rerellent

\section{AVAILABILTY}

\section{$\mathrm{X}$ UNLMITED}

FOR OFFICIAL DISTRIBUTION. DO NOT RELEASE TO NATIONAL TECHNICAL INFORMATION SERVICE (NTIS).

ORDER FROM SUPERINTENDENT OF DOCUMENTS, U.S. GOVERNMENT PRINTING OFFICE, WASHINGTON, DC 20402.

ORDER FROM NATIONAL TECHNICAL INFORMATION SERVICE (NTIS), SPRINGFIELD, VA 22161.
14. NUMBER OF PRINTED PAGES

40

15. PRICE

$\mathrm{A03}$ 


